J Am Chem Soc. 2019 June 26; 141(25): 10068-10081. doi:10.1021/jacs.9b04271.

\title{
Geometric and Electronic Structure Contributions to O-O Cleavage and the Resultant Intermediate Generated in Heme- Copper Oxidases
}

\author{
Andrew W. Schaefer ${ }^{\dagger}$, Antonio C. Roveda Jr. ${ }^{\dagger}$, Anex Jose $^{\dagger}$, and Edward I. Solomon ${ }^{\dagger}$ \\ † Department of Chemistry, Stanford University, Stanford, California 94305, United States
}

\begin{abstract}
This study investigates the mechanism of $\mathrm{O}-\mathrm{O}$ bond cleavage in heme-copper oxidase (HCO) enzymes, combining experimental and computational insights from enzyme intermediates and synthetic models. It is determined that HCOs undergo a proton-initiated O-O cleavage mechanism where a single water molecule in the active site enables proton transfer (PT) from the cross-linked tyrosine to a peroxo ligand bridging the heme $\mathrm{Fe}^{\mathrm{III}}$ and $\mathrm{Cu}^{\mathrm{II}}$, and multiple H-bonding interactions lower the tyrosine $\mathrm{p} K_{\mathrm{a}}$. Due to sterics within the active site, the proton must either transfer initially to the $\mathrm{O}(\mathrm{Fe})$ (a high-energy intermediate), or from another residue over a $\sim 10 \AA$ distance to reach the $\mathrm{O}(\mathrm{Cu})$ atom directly. While the distance between the $\mathrm{H}^{+}$donor $(\mathrm{Tyr})$ and acceptor $(\mathrm{O}(\mathrm{Cu}))$ results in a barrier to PT, this separation is critical for the low barrier to $\mathrm{O}-\mathrm{O}$ cleavage as it enhances backbonding from $\mathrm{Fe}$ into the $\mathrm{O}-\mathrm{O} \sigma^{*}$ orbital. Thus, PT from Tyr precedes $\mathrm{O}-\mathrm{O}$ elongation and is rate-limiting, consistent with available kinetic data. The electron transfers from tyrosinate after the barrier via a superexchange pathway provided by the cross-link, generating intermediate $\mathrm{P}_{\mathrm{M}}$. $\mathrm{P}_{\mathrm{M}}$ is evaluated using available experimental data. The geometric structure contains an $\mathrm{Fe}^{\mathrm{IV}}=\mathrm{O}$ that is $\mathrm{H}$-bonded to the $\mathrm{Cu}^{\mathrm{II}}-\mathrm{OH}$. The electronic structure is a singlet, where the $\mathrm{Fe}^{\mathrm{IV}}$ and $\mathrm{Cu}^{\mathrm{II}}$ are antiferromagnetically coupled through the $\mathrm{H}$-bond between the oxo( $\left.\mathrm{Fe}\right)$ and hydroxo $(\mathrm{Cu})$ ligands, while the $\mathrm{Cu}^{\mathrm{II}}$ and $\mathrm{Tyr}^{*}$ are ferromagnetically coupled due their delocalization into orthogonal magnetic orbitals on the cross-linked His residue. These findings provide critical insights into the mechanism of efficient $\mathrm{O}_{2}$ reduction in HCOs, and the nature of the $\mathrm{P}_{\mathrm{M}}$ intermediate that couples this reaction to proton pumping.
\end{abstract}

\section{Graphical abstract}

Corresponding Authors edward.solomon@stanford.edu. ASSOCIATED CONTENT

Supporting Information. This material is available free of charge via the Internet at http://pubs.acs.org Structural details of the computational model Calculations for kinetics, isotope effects, and magnetic couplings Proton transfer via two water molecules The authors declare no competing financial interests. 


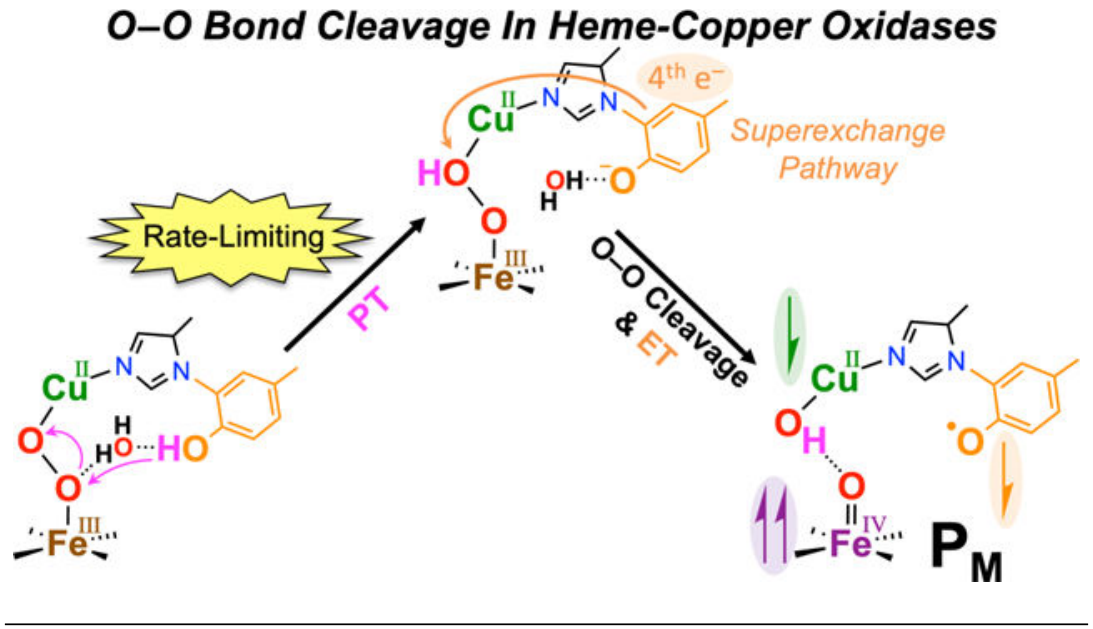

\section{INTRODUCTION}

Heme-copper oxidases (HCOs) comprise a superfamily of metalloenzymes, most notably cytochrome c oxidase $(\mathrm{CcO})$ and ubiquinol oxidase $(\mathrm{UbO})$, which catalyze the $4 \mathrm{e}^{-}$reduction of $\mathrm{O}_{2}$ to $\mathrm{H}_{2} \mathrm{O}$ throughout biology. As this reaction and its reverse are critically relevant for a variety of energy conversion processes, with applications including fuel cells, electrolyzers, solar energy, and biofuels, considerable effort has been committed to understanding the mechanism of $\mathrm{O}_{2}$ reduction in these enzymes. ${ }^{1,2}$ Employing cytochrome $\mathrm{c}$ or ubiquinol as the biological electronsource, this reaction is highly exergonic, yielding a net free energy gain of $\sim 46 \mathrm{kcal} / \mathrm{mol}$, which is efficiently used to drive a proton pumping process that is critical in ATP synthesis. ${ }^{3}$ The active site for $\mathrm{O}_{2}$ reduction, termed the binuclear center ("BNC", Figure 1), consists of a His-ligated heme (heme $\mathrm{a}_{3}$ ) and a closely situated $\mathrm{Cu}$ ion (Cub) coordinated by three His residues, one of which is covalently linked to a nearby Tyr (Tyr244 using bovine $\mathrm{CcO}$ numbering). The Tyr residue is $\mathrm{H}$-bonded to the hydroxyl group of the heme $\mathrm{a}_{3}$ farnesyl chain, approximately $5.5 \AA$ from the $\mathrm{Fe}_{\mathrm{a} 3}$ and $\mathrm{C}_{\mathrm{uB}}{ }^{4}$ Additional metal centers in HCOs include a low-spin heme (heme a) and a binuclear $\mathrm{Cu}\left(\mathrm{Cu}_{\mathrm{a}}\right.$, although absent in ubiquinol oxidase), which are responsible for electron transport to the BNC.

Decades of experimental data have contributed to the current consensus mechanism, in which several intermediates have been observed spectroscopically. ${ }^{2,5}$ As illustrated in Figure $2, \mathrm{O}_{2}$ binds to the fully reduced active site $(\mathbf{R})$, forming a heme-superoxo complex (A), which rapidly undergoes $\mathrm{O}-\mathrm{O}$ cleavage to yield intermediate $\mathbf{P}_{\mathbf{M}}$. When $\mathrm{O}_{2}$ binds to the "mixed-valent" form of the enzyme (where only the active site is reduced), $\mathrm{O}-\mathrm{O}$ cleavage occurs rapidly (yielding $\mathbf{P}_{\mathbf{M}}$, where the $\mathrm{M}$ subscript denotes deriving from the mixed-valent reduced state), indicating that all $4 \mathrm{e}^{-} \mathrm{s}$ required for $\mathrm{O}-\mathrm{O}$ cleavage must be near the BNC. ${ }^{6,7}$ As only $3 \mathrm{e}^{-}$s are supplied by heme a $3\left(\mathrm{Fe}^{\mathrm{II}}\right.$ to $\left.\mathrm{Fe}^{\mathrm{IV}}=\mathrm{O}\right)$ and $\mathrm{C}_{\mathrm{uB}}\left(\mathrm{Cu}^{\mathrm{I}}\right.$ to $\left.\mathrm{Cu}^{\mathrm{II}}-\mathrm{OH}\right)$, it is believed that the fourth e- derives from Tyr244, thus $\mathrm{Pm}$ is formulated as $\mathrm{Fe}^{\mathrm{IV}}=\mathrm{O} / \mathrm{Cu}^{\mathrm{II}}-\mathrm{OH} /$ Tyr*. ${ }^{8}$ Following re-reduction by cytochrome $\mathrm{c}$ or ubiquinol, $\mathrm{H}^{+} / \mathrm{e}^{-}$delivery to the active site generates the $\mathbf{F}$ intermediate, and an additional $\mathrm{H}^{+} / \mathrm{e}^{-}$returns the enzyme to the oxidized state $\left(\mathbf{O}_{\mathbf{H}}\right)$. 
Based on kinetic and computational studies, it is generally viewed that the rate-limiting step in $\mathrm{O}_{2}$ reduction involves breaking the $\mathrm{O}-\mathrm{O}$ bond. ${ }^{9}$ This has attracted great interest in how HCOs perform this step with a low barrier. Although an intermediate between $\mathbf{A}$ and $\mathbf{P}_{\mathbf{M}}$ has not been observed experimentally, extensive investigations with synthetic and computational models have suggested the involvement of a highly reactive peroxo-level species ( $\mathbf{I}_{\mathbf{P}}$ in Figure 2). ${ }^{9-11}$ It has been proposed that this peroxo species serves as the active $\mathrm{H}^{+}$acceptor (rather than the superoxo ligand believed to be present in $\mathbf{A}$ ), highlighting the importance of the $\mathrm{H}^{+}$in $\mathrm{O}-\mathrm{O}$ cleavage. ${ }^{12-14}$ In order to evaluate the feasibility of a peroxo intermediate and elucidate factors that may contribute to its reactivity, numerous model studies have been devoted to understanding the behavior of such a species. ${ }^{15}$ Despite the wealth of literature employing computational and synthetic $\mathrm{HCO}$ models, and in some cases a combination of the two, many details of this process remain unresolved with regards to the $\mathrm{H}^{+}$and $\mathrm{e}^{-}$during $\mathrm{O}-\mathrm{O}$ cleavage, including their source, timing, and means of delivery to the bound $\mathrm{O}_{2}$ molecule.

While it is widely viewed that the source of the $\mathrm{H}^{+}$is Tyr244 (supported by FTIR data and thermodynamics calculations), ${ }^{10,16-19}$ and that the means of $\mathrm{H}^{+}$transfer likely involves a shuttle through water molecules, its predicted timing during $\mathrm{O}-\mathrm{O}$ cleavage has varied considerably throughout the literature. For instance, Sharma et al. ${ }^{20}$ and Blomberg et al. ${ }^{9}$ have recently proposed mechanisms where proton transfer from Tyr occurs prior to formation of $\mathbf{I}_{\mathbf{P}}$, such that the peroxo intermediate is protonated and the barrier involves cleavage of an $\mathrm{FeO}-\mathrm{O}(\mathrm{H}) \mathrm{Cu}$ species. In an earlier study, the same authors presented a similar mechanism except where the proton on the peroxo in $\mathbf{I}_{\mathbf{P}}$ derived from an external donor (delivering an "extra" proton to the active site), and the Tyr remained protonated until after the barrier for $\mathrm{O}-\mathrm{O}(\mathrm{H})$ cleavage. ${ }^{12}$ In contrast, Noodleman et al. have suggested that proton transfer to $\mathbf{I}_{\mathbf{P}}$ (an unprotonated $\mathrm{Fe}-\mathrm{O}-\mathrm{O}-\mathrm{Cu}$ ) comprises the rate-limiting step, early in $\mathrm{O}-\mathrm{O}$ cleavage. ${ }^{21}$ Presenting a fourth possibility, our recent investigation into reactivity in a synthetic model (employing a Fe-O-O-Cu complex and an exogenous phenol) showed experimentally that PT can occur after the barrier and late in O-O cleavage. ${ }^{10}$

Although direct evidence has remained elusive, the fourth $\mathrm{e}^{-}$required for $\mathrm{O}_{2}$ reduction is generally considered to come from Tyr244 (although some reports ${ }^{22,23}$ have suggested other protein residues). Since oxidation of a protonated Tyr would be thermodynamically uphill, the timing of ET can be loosely defined as after the Tyr is deprotonated. However, the mechanism of ET from $\mathrm{Tyr}^{-}$to the cleaving peroxo and its possible contribution in the barrier have scarcely been addressed in the literature.

We have therefore carried out DFT calculations that build on our past experimentally validated study on a hemeperoxo-Cu model complex that undergoes $\mathrm{O}-\mathrm{O}$ bond cleavage upon addition of phenolic substrates. ${ }^{10}$ The present study specifically probes these unresolved questions, drawing on experimental data and comparing results with past computational studies. In the first of three sections, we investigate the mechanism of $\mathrm{O}-\mathrm{O}$ bond cleavage using a computational model of the active site in HCOs. We evaluate key features of the active site in terms of their functional role in $\mathrm{O}-\mathrm{O}$ cleavage, dissecting the reaction into three primary components: proton transfer, electron transfer, and $\mathrm{O}-\mathrm{O}$ elongation. We evaluate possible mechanisms that could enable rapid $\mathrm{O}-\mathrm{O}$ cleavage and 
their thermodynamic/kinetic properties to correlate with experimental data. Our findings offer new insight into the nature of the rate limiting step for O-O cleavage in HCOs, and how the cross-linked Tyr functions as an ideal biological proton donor.

In the second section, we investigate the cross-linked Tyr in terms of its role as the electron donor, with a particular focus on how and when the electron from $\mathrm{Tyr}^{-}$transfers to complete the 4-electron reduction of $\mathrm{O}_{2}$. Our calculations further highlight the importance of the cross-link in HCO function, and reveal a mechanistic dependence on spin state.

In the third section we follow the $\mathrm{O}-\mathrm{O}$ cleavage reaction coordinate to completion and evaluate the final product, intermediate $\mathbf{P}_{\mathbf{M}}$. We generate a series of possible $\mathrm{P}_{\mathbf{M}}$ structures and evaluate their geometric and electronic structures based on available experimental data. The DFT calculations offer valuable insights into the $\mathrm{H}$-bonding interactions and magnetic couplings in $\mathbf{P}_{\mathbf{M}}$. Combining spectroscopic data on $\mathbf{P}_{\mathbf{M}}$ and crystallographic data on the 1electron reduced analog $\left(\mathbf{P}_{\mathbf{R}}\right)$ from recent literature, ${ }^{24-27}$ together with the mechanistic insights from our synthetic and computational modelling of $\mathrm{O}-\mathrm{O}$ cleavage, we converge on a likely geometric and electronic structure of $\mathbf{P}_{\mathbf{M}}$.

The findings presented below reveal several structure-function relationships that are critical for $\mathrm{O}-\mathrm{O}$ cleavage in $\mathrm{HCOs}$, and highlight how nature has optimized the heme/Cu active site to perform efficient $\mathrm{O}_{2}$ reduction. Recent experimental data are applied to the possible $\mathbf{P}_{\mathbf{M}}$ structures from DFT, contributing further insight into the reaction mechanism in the enzyme. As the intermediates following $\mathbf{P}_{\mathbf{M}}\left(\mathbf{F}, \mathbf{O}_{\mathbf{H}}, \mathbf{E}, \mathbf{R}\right)$ are not only spectroscopically observable, but also active in proton pumping, unraveling the geometric and electronic structure of $\mathbf{P}_{\mathbf{M}}$ and how its structure reflects $\mathrm{O}-\mathrm{O}$ cleavage marks a critical step in understanding how HCOs couple $\mathrm{O}_{2}$ reduction to proton pumping.

\section{METHODS}

\section{DFT Calculations.}

Density functional theory (DFT) calculations were performed with the electronic structure package Gaussian16, D.01. These calculations were performed using the B3LYP functional including Grimme dispersion corrections (GD3BJ) within the spin-unrestricted formalism. Basis sets employed for geometry optimizations were as follows: 6-311g* on $\mathrm{Fe} / \mathrm{Cu}, 6-$ $311+\mathrm{g} *$ on $\mathrm{O}, 6-31+\mathrm{g} *$ on all metal-bound $\mathrm{N}$-atoms and $\mathrm{O}-$-bound $\mathrm{H}$ atoms, and 6-31g on all remaining atoms. This method has been experimentally validated by $\mathrm{O}-\mathrm{O}$ cleavage performed by an analogous synthetic model. ${ }^{10} \mathrm{SCF}$ used tight convergence criteria on an ultrafine integration grid, and solvation was included using a polarized continuum model with a dielectric of 4.0. Unless otherwise stated, energetics given in the text are calculated on the singlet surface; triplet energetics differed by less than $1 \mathrm{kcal} / \mathrm{mol}$ and are given in the SI. Thermodynamics were calculated by removing contributions from frozen atoms, which would otherwise introduce artifacts from additional imaginary frequencies. All transition state structures contained one imaginary frequency, and all reactants, intermediates, and products contained only real frequencies. Free energies were calculated at 298 K. For calculation of coupling constants, energies for broken-symmetry states were corrected for 
spin contamination using the Yamaguchi approximate spin projection method. ${ }^{28}$

Visualization of orbitals was performed with Lumo. ${ }^{29}$ See SI for additional details.

\section{RESULTS AND ANALYSIS}

\subsection{Mechanism of O-O Cleavage in HCOs}

Computational evaluation of $\mathrm{O}-\mathrm{O}$ bond cleavage in $\mathrm{CcO}$ was carried out using a model of the active site constructed from a recent crystal structure of bovine $\mathrm{CcO}$ (PDB 3WG7), ${ }^{4}$ shown with a bound peroxo ligand in Figure $3 \mathrm{~A},\left(\{\mathbf{0}\}-\mathbf{I}_{\mathbf{P}}\right)$, the $\{0\}$ indicates that no water molecules are included in the model). To effectively mimic structural constraints imposed by the protein secondary structure, each amino acid residue was truncated at the a-carbon by replacing the backbone with $\mathrm{H}$ atoms, which were then frozen in the calculations. While it is generally absent in HCO computational model studies in the literature, the conserved Val243 residue (sequentially adjacent to Tyr244) was included in the calculations herein, as it lies in close proximity to $\mathrm{C}_{\mathrm{uB}}$ and can sterically inhibit access to the $\mathrm{O}_{2}$ molecule bound in the BNC. Building upon insights from synthetic and computational model studies, ${ }^{10,12,21,30}$ the starting structure for $\mathrm{O}-\mathrm{O}$ cleavage comprises an $\mathrm{Fe}^{\mathrm{III}}-\mathrm{O} 2^{2}-\mathrm{Cu}^{\mathrm{II}}$ core and a protonated Tyr244, denoted as $I_{P}$ (Figure 3A). In accordance with the consensus mechanism, the product structure following $\mathrm{O}-\mathrm{O}$ cleavage (intermediate $\mathrm{P}_{\mathrm{M}}$ ) is described as a $\mathrm{Fe}^{\mathrm{IV}}=\mathrm{O}$ $(\mathrm{S}=1) / \mathrm{Cu}^{\mathrm{II}}-\mathrm{OH} / \mathrm{Y}^{*}$ species, as depicted in Figure 3B. Importantly, while additional $\mathrm{H}^{+}$and $\mathrm{e}^{-}$donors are available near the active site, it has been recently demonstrated that the tyrosine must serve as the $\mathrm{H}^{+}$and $\mathrm{e}^{-}$donor in the net reaction, and that the tyrosine must be deprotonated prior to transferring the electron. ${ }^{10}$

As this net reaction bears close resemblance to that of our recent experimentally-correlated DFT investigation of exogenous phenol-induced $\mathrm{O}-\mathrm{O}$ bond cleavage in a heme-peroxo- $\mathrm{Cu}$ model complex $\left(\left\{\left[(\mathrm{DCHIm})(\mathrm{Fs}) \mathrm{Fe}^{\mathrm{III}}\right]-\left(\mathrm{O} 2^{2-}\right)-[\mathrm{Cu}(\mathrm{II})(\mathrm{AN})]\right\}^{+}\right.$, "LS-AN"), ${ }^{10}$ key insights from the synthetic system can be applied to the $\mathrm{CcO}$ model. In particular, the study with LSAN showed that a low barrier to $\mathrm{O}-\mathrm{O}$ cleavage could be accomplished via two different mechanisms, distinguished fundamentally by whether PT (from phenol interacting directly with the peroxide bridge) occurs before or after the barrier. It was experimentally demonstrated (via a kinetic isotope effect) that in the reaction of the LS-AN model complex, PT occurred primarily after the barrier, indicating that an H-bonding interaction was sufficient to yield a low barrier. This presents a particularly interesting issue with respect to HCOs, since the computational literature has generally invoked a mechanism wherein PT to the bound $\mathrm{O}_{2}$ molecule precedes $\mathrm{O}-\mathrm{O}$ cleavage. . $^{9,12,21}$

Taking advantage of our past results on the well-defined model system, $\{\mathrm{LS}-\mathrm{AN}+\mathrm{PhOH}\}$, the process of $\mathrm{O}-\mathrm{O}$ cleavage was evaluated in $\mathrm{CcO}$. Calculation of the overall thermodynamics for $\mathrm{I}_{\mathrm{P}}$ to $\mathrm{P}_{\mathrm{m}}$ in $\mathrm{CcO}$ (Figure $3 \mathrm{~A}$ to $\mathrm{B}$ ) yields a $\Delta \mathrm{AG}$ of $-11.7 \mathrm{kcal} / \mathrm{mol}$ (calculated at $298 \mathrm{~K}$ ), nearly identical to the value recently reported for $\{\mathrm{LS}-\mathrm{AN}+\mathrm{PhOH}\}$ $(\Delta \mathrm{G}=-10.7 \mathrm{kcal} / \mathrm{mol}),{ }^{10}$ signifying strong similarity between the enzyme and the synthetic model. It is worth recognizing, however, that the experimental O-O cleavage barrier $\left(\Delta \mathrm{G}^{\ddagger}\right)$ in $\mathrm{CcO}$ is $<12.4 \mathrm{kcal} / \mathrm{mol},{ }^{31}$ while the experimental value for $\{\mathrm{LS}-\mathrm{AN}+\mathrm{PhOH}\}$ is $\sim 15$ $\mathrm{kcal} / \mathrm{mol}$. This indicates that the $\mathrm{CcO}$ active site provides a lower intrinsic barrier (i.e. the difference in $\Delta \mathrm{G}^{\dagger}$ is not due to thermodynamics). To evaluate this reaction computationally, 
the B3LYP functional was employed with Grimme dispersion corrections, a method found to provide good agreement with experimental data $\left(\mathrm{KIE}\right.$ and $\left.\Delta \mathrm{G}^{\ddagger}\right)$ for $\{\mathrm{LS}-\mathrm{AN}+\mathrm{PhOH}\}$.

3.1.1 H-Bond Assisted Mechanism-To correlate the kinetic and mechanistic insights from $\{\mathrm{LS}-\mathrm{AN}+\mathrm{PhOH}\}$ to $\mathrm{HCOs}$, the H-bond Assisted mechanism for O-O cleavage was first evaluated for the HCO active site (\{0 $\}$-I $\mathbf{I}_{\mathbf{P}}$, Figure $\left.3 \mathrm{~A}\right)$. A key distinction between the synthetic model and HCOs, however, is that the phenol in $\{\mathrm{LS}-\mathrm{AN}+\mathrm{PhOH}\}$ can interact directly with the peroxo core (Figure 4A), which lowers the barrier to $\mathrm{O}-\mathrm{O}$ homolysis through an H-bonding interaction with the peroxo. In contrast, the donor in HCOs (widely considered Tyr244) is covalently constrained $\sim 5 \AA$ away from the BNC, and O-O homolysis without an $\mathrm{H}$-bond to the peroxo yields a barrier too high relative to experimental data on $\mathrm{CcO}\left(\Delta \mathrm{G}^{\ddagger} \mathrm{calc}=21.9 \mathrm{kcal} / \mathrm{mol}, \Delta \mathrm{G}^{\ddagger} \exp <12.4 \mathrm{kcal} / \mathrm{mol}\right)$. However, water molecules around the active site (crystallographically observed, and generated during turnover) ${ }^{19,24}$ have often been proposed to participate in $\mathrm{H}^{+}$delivery to $\mathrm{O} 2$, and can approach to $\mathrm{H}$-bond directly to the bridging peroxo. Moving a water molecule from bulk into the active site in $\{\mathbf{0}\}-\mathbf{I}_{\mathbf{P}}$ (as in $\{\mathbf{1 C}\}-\mathbf{I}_{\mathbf{P}}$ in Figure 4B; $\{1 \mathrm{C}\}$ indicates the inclusion of one water molecule near the Ocu atom) is calculated to be a nearly thermoneutral process $(\Delta \mathrm{H}=-8 \mathrm{kcal} / \mathrm{mol}, \Delta \mathrm{G}=$ $+2 \mathrm{kcal} / \mathrm{mol})$.

The H-bond Assisted mechanism can therefore be mimicked in the enzyme by elongating the $\mathrm{O}-\mathrm{O}$ bond of the structure shown in Figure 4B. However, the calculated barrier including this H-bond ("TShb" in Figure 5) is still too large $\left(\Delta \mathrm{G}^{\ddagger}=21.2 \mathrm{kcal} / \mathrm{mol}\right)$. While the H-Bond Assisted mechanism gave a lower barrier in $\{\mathrm{LS}-\mathrm{AN}+\mathrm{PhOH}\}\left(\Delta \mathrm{G}^{\ddagger}=16.5 \mathrm{kcal} / \mathrm{mol}\right)$, the higher $\Delta \mathrm{G}^{\ddagger}$ for $\mathrm{H}$-Bond Assisted cleavage in $\mathrm{CcO}$ can be attributed to weaker $\mathrm{H}$-bonding from $\mathrm{H}_{2} \mathrm{O}$ relative to phenol (using $\mathrm{H}_{2} \mathrm{O}$ with LS-AN raises its $\Delta \mathrm{G}^{\ddagger}$ to $19.2 \mathrm{kcal} / \mathrm{mol}$ ). Further, the calculations show that deprotonating the active site $\mathrm{Tyr}$ in the $\mathrm{CcO}$ model (thereby providing a low-potential electron source) does not result in a lower barrier for O$\mathrm{O}$ homolysis, as the electron does not transfer from $\mathrm{Tyr}^{-}$before the barrier (vide infra). It should be noted that the above energetics were calculated on the broken-symmetry singlet surface; calculation on the triplet surface yields higher barriers to $\mathrm{O}-\mathrm{O}$ homolysis because the $\mathrm{Cu}$-oxyl species that is forming in the transition state is a singlet on the overall triplet surface, which is less stable than the triplet $\mathrm{Cu}$-oxyl formed on the overall singlet surface. In all, these results indicate that an $\mathrm{H}$-bond from $\mathrm{H}_{2} \mathrm{O}$ would not lower the barrier to $\mathrm{O}-\mathrm{O}$ cleavage enough to agree with the observed kinetics in HCOs.

3.1.2 Proton-Initiated Mechanism-The second mechanism evaluated for the O-O cleavage reaction of $\{\mathrm{LS}-\mathrm{AN}+\mathrm{PhOH}\}$, "Proton-Initiated" (PI), involves PT from phenol to the peroxo early in O-O cleavage. In the LS-AN model this was found to produce a higher $\mathrm{O}-\mathrm{O}$ cleavage barrier and incorrect $\mathrm{KIE}$ relative to experiment. For $\mathrm{CcO}$, the PI mechanism can be accomplished by transferring a $\mathrm{H}^{+}$from the Tyr to the peroxo bridge via a Grotthuss mechanism (a concerted movement of protons through water molecules). It has been reported that no $\mathrm{H}^{+}$uptake is observed in $\mathrm{CcO}$ before $\mathrm{O}-\mathrm{O}$ cleavage, meaning the $\mathrm{H}^{+}$must derive from an internal donor. ${ }^{32}$ Most computational HCO models in the literature have invoked a bridge from Tyr244 to the $\mathrm{o}_{\mathrm{cu}}$ atom consisting of one or two water molecules, shuttling the tyrosyl proton to $\mathrm{O}_{\mathrm{cu}}$ (which has a higher $\mathrm{H}^{+}$affinity than $\mathrm{O}_{\mathrm{Fe}}$ by $\sim 9 \mathrm{kcal} / \mathrm{mol}$ ). 
12 However, our calculations reveal that a valine residue (Val243) conserved in the active sites of HCOs sterically prohibits a direct bridge between Tyr244 and $\mathrm{O}_{\mathrm{cu}}$ (region marked by a gray $\mathrm{X}$ in Figure 6), yet this residue has not been included in the past computational HCO models. Nevertheless, a water molecule may form a bridge between Tyr244 to the $\mathrm{O}_{\mathrm{Fe}}$ atom of the peroxo (marked by the red circle in Figure 6, corresponding to structure $\{\mathbf{1 F}\}-\mathbf{I}_{\mathbf{p}}(\{1 \mathrm{~F}\}$ includes one water molecule able to interact with the $\mathrm{O}_{\mathrm{Fe}}$ and/or Tyr) Section 3.2.1 below), where both $\mathrm{O}_{\mathrm{Tyr}} \ldots \mathrm{O}_{\text {water }}$ and $\mathrm{O}_{\text {water }} \ldots \mathrm{O}_{\mathrm{Fe}}$ distances are $<2.7 \AA$. It is thermodynamically favorable to bind the water molecule in $\{\mathbf{1 F}\}-\mathbf{I}_{\mathbf{p}}$ from bulk, with a calculated $\Delta \mathrm{G}_{\text {binding }}=$ $-0.4 \mathrm{kcal} / \mathrm{mol}\left(\Delta \mathrm{H}_{\text {binding }}=-9.7 \mathrm{kcal} / \mathrm{mol}\right)$.

3.1.2.1 Proton Transfer from Tyr: To evaluate proton transfer from Tyr to the peroxo $\mathrm{O}_{\mathrm{Fe}}$ via a water molecule $\left(\{\mathbf{1 F}\}-\mathbf{I}_{\mathbf{p}} \rightarrow\{\mathbf{I F}\}-\mathbf{H}_{\mathbf{F e}}\right.$, Figure 7), a 2-dimensional potential energy surface (PES) was calculated involving motion of both protons active in transfer $\left(\mathrm{O}_{\text {Tyr }} \cdots \mathrm{H} \cdots \mathrm{O}_{\text {water }}\right.$ and $\left.\mathrm{O}_{\text {water }} \cdots \mathrm{H} \cdots \mathrm{O}_{\mathrm{Fe}}\right)$. This $2 \mathrm{D}$ PES led to the convergence of a true transition state for PT through the bridging water molecule, yielding a barrier of $\Delta \mathrm{G}^{\ddagger}=13.7$ $\mathrm{kcal} / \mathrm{mol}\left(\Delta \mathrm{H}^{\ddagger}=10.4 \mathrm{kcal} / \mathrm{mol}\right)$. The thermodynamic cost of transferring the $\mathrm{H}^{+}$to $\mathrm{OFe}$ (forming $\{\mathbf{I F}\}-\mathrm{H}_{\mathrm{Fe} 1}$, Figure 7) is $\Delta \mathrm{G}=+12.7 \mathrm{kcal} / \mathrm{mol}(\Delta \mathrm{H}=+9.4 \mathrm{kcal} / \mathrm{mol})$.

Elongating the $\mathrm{O}-\mathrm{O}$ bond with the proton on $\mathrm{O}_{\mathrm{Fe}}$ yields a high barrier to $\mathrm{O}-\mathrm{O}$ cleavage, indicating that the proton must rearrange to bind the $\mathrm{O}_{\mathrm{cu}}$ atom of the peroxo (as in $\{\mathbf{1 F}\}-\mathbf{H}$, far right in Figure 7) before O-O cleavage. Note that the water in $\{\mathbf{1 F}\}-\mathbf{I}_{\mathbf{p}}$ in Figure 7 cannot access the $\mathrm{O}_{\mathrm{cu}}$ atom directly without a large distortion in the $\mathrm{Cu}$ ligand field (which would give a $\Delta \mathrm{G}^{\ddagger}>20 \mathrm{kcal} / \mathrm{mol}$ ), supporting that the proton from Tyr should transfer initially to the $\mathrm{O}_{\mathrm{Fe}}$ atom. After PT from Tyr to yield $\{\mathbf{1 F}\}-\mathbf{H}_{\mathbf{F e} \mathbf{1}}$, the $\mathrm{H}^{+}$on OFe rotates away from the water molecule (for which $\Delta \mathrm{G}^{\ddagger}=13.5 \mathrm{kcal} / \mathrm{mol},\{\mathbf{1 F}\}-\mathbf{H}_{\mathbf{F e} 1} \rightarrow\{\mathbf{1 F}\}-\mathbf{H}_{\mathbf{F e} 2}$ in Figure 7). Finally, a barrierless proton shift from $\mathrm{O}_{\mathrm{Fe}}$ to $\mathrm{O}_{\mathrm{cu}}$ yields $\{\mathbf{1 F}\}-\mathbf{H}$ in Figure 7.

While increasing the number of bridging water molecules has been shown to lower the barrier for Grotthuss mechanisms, ${ }^{33,34}$ our calculations show that incorporating a second water molecule in the bridge between Tyr and $\mathrm{O}_{\mathrm{Fe}}$ (yielding the model denoted $\{\mathbf{2 F}\}$, see SI Section 2 for additional details) would not effectively lower the PT barrier in $\mathrm{CcO}$. This is due to the $\mathrm{H}_{2} \mathrm{O} \cdots \mathrm{HO}_{\mathrm{Fe}} \mathrm{H}$-bond in $\{\mathbf{1 F}\}-\mathbf{H}_{\mathrm{Fe}}$ being broken in the $\mathrm{H}-\mathrm{O}_{\mathrm{Fe}}$ rotation step (Figure 7, $\{\mathbf{1 F}\}-\mathbf{H}_{\mathrm{Fe} 1} \rightarrow\{\mathbf{1 F}\}-\mathbf{H}_{\mathbf{F e} 2}$, which causes this step to have a similar barrier and transition state structure for one or two bridging water molecules. Nevertheless, the barrier to PT calculated above for one bridging water molecule $(13.7 \mathrm{kcal} / \mathrm{mol})$ is sufficiently close to the $12.4 \mathrm{kcal} / \mathrm{mol}$ experimental limit to be a good candidate for the active mechanism.

3.1.2.2 O-O Cleavage of $\mathrm{Fe}^{\mathrm{III}}$-O-O(H)-C $\mathrm{Cu}^{\mathrm{II}}$ : Evaluating the barrier to O-O bond cleavage of $\{\mathbf{1 F}\}-\mathbf{H}$ (Figure 8), where the $\mathrm{H}^{+}$from Tyr is on $\mathrm{O}_{\mathrm{cu}}$ and a water molecule is $\mathrm{H}$-bonded to the $\mathrm{Tyr}^{-}$, a transition state was found at an O-O distance of $1.84 \AA$ with an energy of $\Delta \mathrm{G}^{\ddagger}$ of $11.5 \mathrm{kcal} / \mathrm{mol}$ (on both the singlet and triplet spin surfaces). This result has two crucial implications. First, O-O cleavage of $\{\mathbf{1 F}\}-\mathbf{H}$ involves a sufficiently low barrier to be consistent with kinetic data on $\mathrm{CcO}$. Second, it presents a lower barrier to O-O cleavage than the H-Bond Assisted mechanism (vide supra), indicating that a Proton-Initiated mechanism is favored in HCOs, in contrast to the behavior observed in $\{\mathrm{LS}-\mathrm{AN}+\mathrm{PhOH}\}$. This change in mechanism for the enzyme relative to the model can be understood based on two key 
factors responsible for favoring one mechanism over the other that were identified from evaluation of $\{\mathrm{LS}-\mathrm{AN}+\mathrm{PhOH}\}$. Most notably, the Proton-Initiated mechanism is favored by: 1) employing a more acidic proton donor, and 2) by enhancing electron donation into the peroxo, which increases its basicity. Applying these insights to HCOs, we evaluate below how the active site in $\{\mathbf{1 F}\}-\mathbf{H}$ enables O-O cleavage with a barrier that is half that of the Proton-Initiated O-O cleavage of LS-AN (11.5 vs. 25 kcal/mol, TS $\mathbf{P I}$ in Figure 8), highlighting key structure-function relationships in HCOs.

The change in behavior calculated for O-O cleavage of $\{\mathbf{1 F}\}-\mathrm{H}$ compared to $\{\mathrm{LS}-\mathrm{AN}+$ $\mathrm{PhOH}\}$ derives from a combination of structural and electronic differences in their ProtonInitiated potential energy surface. While the overall thermodynamics for product formation $\left(\mathbf{I}_{\mathbf{P}} \rightarrow \mathbf{P}_{\mathbf{M}}\right.$, Figure 8$)$ are very similar, approximately $\Delta \mathrm{G}^{\circ}=-11 \mathrm{kcal} / \mathrm{mol}$, the energetic cost of PT from Tyr to $\mathrm{O}_{\mathrm{cu}}$ (i.e. $\left.\mathbf{I}_{\mathbf{P}} \rightarrow \mathbf{H}\right)$ is much lower in $\{\mathbf{1 F}\}(4 \mathrm{kcal} / \mathrm{mol})$ than in $\{\mathrm{LS}-\mathrm{AN}+$ $\mathrm{PhOH}\}(13 \mathrm{kcal} / \mathrm{mol})$. This difference is attributable to the lower $\mathrm{pKa}$ of the Tyr in CcO compared to the phenolate in LS-AN, as the Tyr in $\{\mathbf{1 F}\}$ has two H-bonds to stabilize the deprotonated anion (one from the water molecule and one from the farnesyl hydroxyl group, see $\{\mathbf{1 F}\}-\mathbf{H}$ in Figure 8), whereas the phenol in LS-AN is stabilized by only one H-bond (from the $\mathrm{O}_{\mathrm{cu}}$ ). Removing the water molecule in $\{\mathbf{1 F}\}$ raises the energetic cost of transferring the Tyr $\mathrm{H}^{+}$by $\sim 7 \mathrm{kcal} / \mathrm{mol}$. This result also highlights a likely function of the hydroxy group on the farnesyl side chain of the active site heme, as it is favorably positioned to $\mathrm{H}$-bond to the tyrosinate and assist in lowering its $\mathrm{pK}_{\mathrm{a}}$. Another structural component of the active site that may act to lower the Tyr $\mathrm{pK}_{\mathrm{a}}$ is the His-Tyr cross-link, which can increase $\pi$-delocalization and inductive effects to stabilize the tyrosinate anion. ${ }^{35}$ Based on synthetic modelling with substituted phenols, the cross-link is estimated to lower the Tyr $\mathrm{pK}_{\mathrm{a}}$ by $\sim 1.5$ units, or $2 \mathrm{kcal} / \mathrm{mol}^{36,37}$

Also from Figure 8, starting from the $\mathrm{H}$ structures there is a lower barrier from $\mathrm{O}-\mathrm{O}$ cleavage (i.e. $\left.\mathbf{H} \rightarrow \mathbf{T S} \mathbf{S}_{\mathbf{p} 1}\right)$ in $\{\mathbf{1 F}\}(7.5 \mathrm{kcal} / \mathrm{mol})$ compared to $\{\mathrm{LS}-\mathrm{AN}+\mathrm{PhOH}\}(12 \mathrm{kcal} / \mathrm{mol})$. This difference derives from a greater extent of electron donation from $\mathrm{Fe}$ into the peroxo (via backbonding from the $\mathrm{Fe} \mathrm{d}_{\boldsymbol{\pi}}$ orbital into the $\mathrm{O}_{2} \sigma^{*}$ ) in $\{\mathbf{1 F}\}-\mathbf{T S} \mathbf{S}_{\mathbf{p} 1}$ compared to LS-AN. The proton on $\mathrm{O}_{\mathrm{cu}}$ enhances ET from $\mathrm{Fe} \mathrm{d}_{\pi}$ by lowering the energy of the peroxo $\sigma^{*}$ orbital (therefore activating the $\mathrm{O}-\mathrm{O}$ bond for cleavage). Comparing $\{\mathbf{1 F}\}$ to LS-AN, the H-bond from phenolate to the $\mathrm{H}^{+}$on $\mathrm{O}_{\mathrm{cu}}$ in LS-AN weakens the $\mathrm{H}-\mathrm{O}_{\mathrm{cu}}$ bond and lessens this effect. 38

We also considered whether the cross-linked tyrosine participates in ET before the barrier, as this would both increase the negative charge on the peroxo (raising its proton affinity and lowering the energetic cost of PT from Tyr), and increase $<\mathrm{DI}>\mathrm{O} 2^{2-} a^{*}</ \mathrm{DI}>$ occupation (therefore assisting O-O cleavage). However, our calculations (see also Section 3.2) indicate that electron transfer from $\mathrm{Tyr}^{-}$does not occur until after the transition state, and therefore does not impact the barrier. Taken together the above results demonstrate the active site in $\mathrm{CcO}$ lowers the barrier for Proton-Initated O-O cleavage relative to the synthetic model \{LS$\mathrm{AN}+\mathrm{PhOH}$ \} by providing both a more acidic proton source (due to H-bond stabilization of the resultant $\mathrm{Tyr}^{-}$), and enhanced backbonding from Fe into the peroxo $\sigma^{*}$ LUMO (due to the stronger $\mathrm{H}-\mathrm{O}_{\mathrm{cu}}$ bond) before the barrier. 
3.1.2.3 Alternative Proton-Initiated O-O Cleavage: Since the $\mathrm{e}^{-}$from Tyr ${ }^{-}$transfers after the transition state, a key implication is that the Tyr is only impacting the barrier via the $\mathrm{H}^{+}$. This suggests that the $\mathrm{H}^{+}$bound to $\mathrm{O}_{\mathrm{cu}}$ could derive from a donor other than the active site Tyr, such that Tyr is not deprotonated until after the barrier. ${ }^{12,17,39,40}$ This would require direct $\mathrm{H}^{+}$transfer to the peroxide Ocu and avoid the energy cost of going through a protonated $\mathrm{O}_{\mathrm{Fe}}$ intermediate $\left(\mathbf{I}_{\mathbf{P}} \rightarrow \mathbf{H}_{\mathbf{F e} 2}\right.$, Figure 7). Given the presence of alternative $\mathrm{H}^{+}$ donors near the active site in $\mathrm{CcO}$ (such as Tyr129 and two Arg located $\sim 10 \AA$ from Cub), a $\mathrm{H}^{+}$could alternatively be shuttled to the $\mathrm{O}_{\mathrm{cu}}$ atom via 4 or more waters in a Grotthuss mechanism. ${ }^{41,42}$ In this case, the PT pathway would include a water molecule $\mathrm{H}$-bonded to $\mathrm{O}_{\text {cu }}$, generating the active site $\mathrm{Fe}^{\mathrm{III}}-\mathrm{OO}(\mathrm{H})-\mathrm{Cu}^{\mathrm{II}}$ species shown in $\{\mathbf{1 C}+\}-\mathbf{H}$ (Figure 9, the (+) signifies a proton supplied by a nearby donor not included in the model). After PT, the water molecule in $\{\mathbf{1 C}+\}-\mathbf{H}$ is weakly bound to the $\mathrm{O}_{\mathrm{cu}} \mathrm{H}\left(\Delta \mathrm{H}_{\text {binding }}=-7.3 \mathrm{kcal} / \mathrm{mol}\right.$, $\Delta \mathrm{G}_{\text {binding }}=+3 \mathrm{kcal} / \mathrm{mol}$ ) and may freely dissociate.

An externally derived $\mathrm{H}^{+}$shuttled directly to $\mathrm{O}_{\mathrm{cu}}$ can enable rapid $\mathrm{O}-\mathrm{O}$ cleavage provided three criteria are met: 1) the barrier to Grotthuss-mediated PT to $\mathrm{O}_{\mathrm{cu}}$ is $<12.4 \mathrm{kcal} / \mathrm{mol}, 2$ ) the thermodynamic cost of PT to the peroxo is $\leq 5 \mathrm{kcal} / \mathrm{mol}$, and 3) the water molecule involved in $\mathrm{PT}$ to $\mathrm{O}_{\mathrm{cu}}$ dissociates early in $\mathrm{O}-\mathrm{O}$ cleavage (H-bonding to $\mathrm{Cu}-\mathrm{OH}$ adds 5 $\mathrm{kcal} / \mathrm{mol}$ to the barrier). Studies of Grotthuss mechanisms have reported barriers to proton migration that are typically $10 \mathrm{kcal} / \mathrm{mol}$ or lower, depending on the local environment and separation between water molecules. ${ }^{34,43,44} \mathrm{In} \mathrm{CcO}$, the endergonicity of PT will add to the barrier (see SI). Nevertheless, using the same thermodynamics for PT from the active site $\operatorname{Tyr}(4 \mathrm{kcal} / \mathrm{mol})$ and an upper estimate of the intrinsic barrier for Grotthuss mechanisms (10 $\mathrm{kcal} / \mathrm{mol}$ ), the effective barrier for PT would still be only $12.1 \mathrm{kcal} / \mathrm{mol}{ }^{45,46}$ If the $\mathrm{pKa}$ of the "alternative" amino acid donor is $2 \log$ units higher than the active site Tyr (resulting in a $\Delta \mathrm{G}$ for PT of $6.7 \mathrm{kcal} / \mathrm{mol}$ ), the PT barrier would raise to $13.6 \mathrm{kcal} / \mathrm{mol}$, comparable to PT from the active site Tyr (Section 3.1.2.1).

Taken together, the above results show that a $\mathrm{H}+$ donor outside the active site could provide a low barrier for Proton-Initiated O-O cleavage that is comparable to the barrier found for PT from Tyr (11.5 kcal/mol, Figure 8). After the barrier, since oxidation of Tyr- is required by thermodynamics (vide supra), the Tyr must deprotonate (e.g. into bulk via the farnesyl hydroxyl group) and transfer its electron to the cleaving $\mathrm{O}-\mathrm{OH}$, generating the $\mathrm{Fe}^{\mathrm{IV}}=\mathrm{O} / \mathrm{Cu}^{\mathrm{II}}$ $\mathrm{OH} /$ Tyr* products (which may have the water molecule bound to the $\mathrm{Cu}-\mathrm{OH}$, see $\{\mathbf{1 C}\}-\mathbf{P}_{\mathbf{M}}$, see Section 3.3). In all, this presents an alternative mechanism wherein the cross-linked Tyr does not actively contribute until after the barrier, yet still provides the tyrosinate electron necessitated by thermodynamics to generate the $\mathrm{O}-\mathrm{O}$ cleaved product, $\mathbf{P}_{\mathbf{M}}$.

\subsubsection{Kinetics and Isotope Effects in Proton-Initiated O-O Cleavage: The above} results describe two possible mechanisms for $\mathrm{O}-\mathrm{O}$ cleavage in $\mathrm{CcO}$. While both are ProtonInitiated in nature, they differ by the active proton donor. In both cases, proton transfer and $\mathrm{O}-\mathrm{O}$ cleavage occur in a sequential manner, and the barriers for both steps are comparable (either could be rate-limiting). However, kinetic data on $\mathrm{CcO}$ have shown that the decay of $\mathbf{A}$ to $\mathbf{P}_{\mathbf{M}}$ has a deuterium kinetic isotope effect (KIE) of 1.4-1.9. ${ }^{31}$ We therefore calculated KIEs (see SI) for the Proton-Initiated mechanisms above (with models $\{\mathbf{1 C}\}$ and $\{\mathbf{I F}\}$ ), evaluating both the PT and $\mathrm{O}-\mathrm{O}$ cleavage processes, as it is not clear from experiment which 
step is rate-limiting. The results are summarized in Scheme 1. In the mechanism initiated by PT from Tyr to $\mathrm{O}_{\mathrm{Fe}}$ (model $\{\mathbf{I F}\}$ ), the KIE calculated for PT via a Grotthuss mechanism with one water molecule $\left(\{\mathbf{1 F}\}-\mathbf{I}_{\mathbf{P}} \rightarrow\{\mathbf{1 F}\}-\mathbf{H}_{\mathbf{F e} 1}\right.$, Figure 7$)$ is $k_{\mathrm{H}} / k_{\mathrm{D}}=8.3$. The subsequent step, in which the proton rearranges onto the $\mathrm{O}_{\mathrm{cu}}$ atom, $\{\mathbf{1 F}\}-\mathbf{H}_{\mathrm{Fe} \mathbf{1}} \rightarrow\{\mathbf{1 F}\}-\mathbf{H}_{\mathbf{F e} 2}$ (the $\Delta \mathrm{G}^{\ddagger}$ is comparable to the preceding PT step), has a calculated $k_{\mathrm{H}} / k_{\mathrm{D}}$ is 1.4 . Note that the results obtained with a one-water bridge are similar to those with a two-water bridge (see SI). In the mechanism involving PT from an external donor (model $\{\mathbf{1 C}\}$ ) a KIE for Grotthussmediated PT can be estimated from literature on biological Grotthuss mechanisms, which are generally on the order of 1.4-3 for transfer over several water molecules ${ }^{47,48}$ (although KIEs can increase to 5 or greater for transfer through only one or two water molecules). ${ }^{33}$ Finally, regardless of the mechanism of proton transfer, the $\mathrm{KIE}$ for $\mathrm{FeO}-\mathrm{O}(\mathrm{H}) \mathrm{Cu}$ cleavage (using the transition state $\{\mathbf{1 F}\}$-TS $\mathbf{P I}$ ) is calculated to be $k_{\mathrm{H}} / k_{\mathrm{D}}=0.95$, an inverse KIE. Given that the experimental KIE is in the range of 1.4-1.9, these results suggest that proton transfer, rather than $\mathrm{O}-\mathrm{O}$ cleavage, is rate-limiting in HCOs. If the proton that initiates $\mathrm{O}-\mathrm{O}$ cleavage derives from the cross-linked Tyr, the rate-limiting step involves proton migration from the $\mathrm{O}_{\mathrm{Fe}}$ atom to the $\mathrm{O}_{\mathrm{Cu}}$ atom.

In all, the calculations presented above and the $\mathrm{HCO}$ literature to-date have contributed several possible mechanisms for O-O cleavage, varying in: 1) the identity of the active proton donor, 2) participation and orientation of water molecules, 3) timing and involvement of PT and ET from Tyr, and 4) overall spin state. While the literature has reached a consensus that the $\mathrm{O}_{\mathrm{Cu}}$ atom is protonated when the $\mathrm{O}-\mathrm{O}$ bond is broken, the rate-limiting step (PT or $\mathrm{O}-\mathrm{O}(\mathrm{H})$ cleavage) remains an open issue. ${ }^{9,21}$ The calculations herein evaluate both processes, and suggest that the barrier to $\mathrm{O}-\mathrm{O}$ cleavage in HCOs (A to $\mathrm{P}_{\mathrm{m}}$ ) is proton transfer to $\mathrm{O}_{\mathrm{cu}}$. This is due to sterics within the active site, which require that PT must involve either a higher-energy intermediate where the $\mathrm{O}_{\mathrm{Fe}}$ atom is protonated (model $\{\mathbf{I F}\}$ ), or PT over a large $(\sim 10 \AA)$ distance to go directly to the $\mathrm{O}_{\text {cu }}$ atom (model $\{\mathbf{1 C}\}$ ).

Nevertheless, these results describe two possible mechanisms for O-O cleavage in HCOs, where both could provide a barrier $(<12.4 \mathrm{kcal} / \mathrm{mol})$ and KIE $(1.4-1.9)$ in agreement with experimental estimates.

\subsection{Electron Flow from Tyr}

While the results above considered multiple possible origins for the $\mathrm{H}^{+}$involved in lowering the barrier to O-O cleavage, our calculations have shown that given the available electron sources near the active site (tryptophan and tyrosine), tyrosinate is the only electron donor able to afford thermodynamically favorable $\mathrm{O}-\mathrm{O}$ cleavage. Although the literature has widely proposed that Tyr provides the fourth electron, we have examined the active ET process to understand the connection between the structure (Cu-His-Tyr linkage) and function (electron transfer) from the cross-linked tyrosine.

Examining the electronic structure over the reaction coordinate for $\mathrm{O}-\mathrm{O}$ cleavage from transition state $\left(r(\mathrm{O}-\mathrm{O})=1.83 \AA\right.$ ) to product (TSpi to $\mathrm{P}_{\mathrm{M}}$, Figure 8$)$, the electron flow from $\mathrm{Tyr}^{-}$to the peroxo is observed as a rapid transfer at an $\mathrm{O}-\mathrm{O}$ distance of $\sim 2.0 \AA$. The calculations show that as the $\mathrm{O}-\mathrm{O}$ bond elongates, the $\mathrm{O}_{2} \sigma^{*}$ progressively lowers in energy, eventually becoming isoenergetic with the $\mathrm{Tyr}^{-} \mathrm{HOMO}$. This enables $\mathrm{ET}$ from $\mathrm{Tyr}^{-}$, where 
the transferring $\mathrm{e}^{-}$has an alpha spin to pair with the beta $\mathrm{e}^{-}$transferring from $\mathrm{LS} \mathrm{Fe}^{\mathrm{III}}$, which completes the 4-electron reduction of $\mathrm{O}_{2}$. Prior to transfer, the $\mathrm{Tyr}^{-}$electron resides in an MO that is localized primarily on the Tyr ring (a HOMO at $\mathrm{O}-\mathrm{O}=2.0 \AA$ in Figure 10), although it mixes with the $\pi$ HOMO on the His, which has efficient $\pi$ overlap. To examine the orbitals involved in this process, we have evaluated both the singlet and triplet surfaces, using the simplified model without water molecules $(\{\mathbf{0}\})$.

On the singlet surface $(\mathrm{Fe} 1 / \mathrm{Cu} \downarrow)$, the beta-spin $\mathrm{Cu}^{\mathrm{II}}$ has an alpha hole in the $\mathrm{dx}^{2}-\mathrm{y}^{2}$ orbital. The $\mathrm{Cu}$ hole is tilted and has overlap with the occupied $\mathrm{n}$ valence orbital on the His, delocalizing onto the Tyr via a superexchange pathway through the His $\pi$ orbital (Figure 10). This results in partial occupation of the $\mathrm{Cu} \mathrm{dx}^{2}-\mathrm{y}^{2}$ (alpha) and oxidation of the Tyr HOMO. Elongation of the $\mathrm{O}-\mathrm{O}$ past the TS brings its $\sigma^{*}$ down in energy so that the a $\mathrm{e}^{-}$ propagates from the Tyr HOMO into the $\mathrm{O}_{2}{ }^{2-} \sigma^{*}$ via the $\mathrm{Cu}$ and His. Therefore, the His-Tyr cross-link provides a superexchange pathway for the $\mathrm{Cu} \mathrm{dx}^{2}-\mathrm{y}^{2}$ a unoccupied orbital to gain occupied character from the Tyr, such that its $\mathrm{e}^{-}$can readily transfer into the $\mathrm{O}_{2}{ }^{2-} \sigma^{*}$ as ET becomes energetically favorable. The tilting of the $\mathrm{Cudx} \mathrm{du}^{2}-\mathrm{y}^{2}$ orbital off the $\mathrm{Cu}-\mathrm{N}_{\mathrm{His}}$ axis, and therefore the formation of the superexchange pathway occurs after the transition state (but before complete $\mathrm{O}-\mathrm{O}$ cleavage) and ET is triggered by the driving force at the elongated $\mathrm{O}-\mathrm{O}(\mathrm{H})$ distance.

On the overall triplet surface $(\mathrm{Fe} 1 / \mathrm{Cu} 1)$, all alpha d-orbitals on $\mathrm{Cu}^{\mathrm{II}}$ are occupied, resulting in an ET mechanism that involves $\mathrm{e}^{-}$hole transfer (Figure 11) through filled valence orbitals. Following the a LUMO orbital character over O-O elongation (top half of Figure 11), the hole propagates from the unoccupied $\mathrm{O}_{2}{ }^{2-} \sigma^{*}$ orbital, through the occupied aa $\mathrm{d}_{\mathrm{yz}}\left(\pi^{*}\right)$ orbital on $\mathrm{Cu}$ and the occupied $\pi$ orbital on the His, terminating with the Tyr HOMO. Thus, on the triplet surface, the cross-link also provides a superexchange pathway between the $\mathrm{Tyr}^{-} \mathrm{HOMO}$ and the $\mathrm{O}_{2} \sigma^{*}$ LUMO, but via a doubly occupied $\mathrm{Cu}$ orbital.

Taken together, these results highlight several key aspects of electron flow from Tyr. First, the electron transfers after the barrier to $\mathrm{O}-\mathrm{O}(\mathrm{H})$ cleavage, occurring as a barrierless ET process driven by the $\mathrm{O}_{2} \sigma^{*}$ energy decreasing below the Tyr HOMO. Second, the spin and ground state of $\mathrm{Cu}$ are unchanged during charge flow into the $\mathrm{O} 2 \sigma^{*}$. Third, the charge propagates through an occupied orbital on the His (as well as the $\mathrm{Cu}$, on the triplet surface), and is therefore best described as hole transfer through the cross-link. Fourth, the observed ET mechanism differs fundamentally for the singlet and triplet surfaces, primarily due to the hole on $\mathrm{Cu}$ having either the same (triplet) or opposite (singlet) spin as the e- transferring into the $\mathrm{O}^{2-} \sigma^{*}$ orbital. Thus, in addition to keeping the $\mathrm{Tyr}^{-}>5 \AA$ from the peroxide, the $\mathrm{Cu}$-His-Tyr cross-link provides a means for electron transfer from the Tyr ${ }^{-}$into the $\mathrm{O}_{2}{ }^{2-} \sigma^{*}$, regardless of overall spin state.

\subsection{Geometric and Electronic Structure of $\mathbf{P}_{\mathbf{m}}$}

While multiple possible structures for $\mathrm{P}_{\mathrm{m}}$ have been presented in the literature, it is generally considered to be comprised of three common components: an $\mathrm{S}=1 \mathrm{Fe}^{\mathrm{IV}}=\mathrm{O}$, an $\mathrm{S}=1 / 2 \mathrm{cu}^{\mathrm{II}}$, and an $\mathrm{S}=1 / 2 \mathrm{Tyr}^{\bullet} .{ }^{20,25,26,49-51}$ The $\mathrm{P}_{\mathrm{m}}$ product generated in the DFT calculations depends on the reaction mechanism, including interactions with nearby water molecules and spin state. The results in sections 3.1 and 3.2 above demonstrate how PT from the active site Tyr (or 
alternatively another nearby donor) initiates $\mathrm{O}-\mathrm{O}$ cleavage with a low barrier that is consistent with kinetic data, which can be accomplished on either the singlet or triplet spin surfaces. Therefore, we have evaluated the possible structures for $\mathrm{P}_{\mathrm{m}}$ deriving from these models in terms of their geometric and electronic characteristics.

The structural information presently available for $\mathrm{P}_{\mathrm{m}}$ derives from $\mathrm{rR}$ and EPR. The $\mathrm{rR}$ data indicate that $\mathrm{P}_{\mathrm{m}}$ has a strong $\mathrm{Fe}-\mathrm{O}$ bond $\left(\mathrm{V}_{\mathrm{Fe}-\mathrm{O}}=804 \mathrm{~cm}^{-1}\right)$ that is insensitive to both $\mathrm{H} / \mathrm{D}$ substitution and changes in $\mathrm{pH},{ }^{25}$ suggesting an $\mathrm{Fe}^{\mathrm{IV}}=\mathrm{O}$ with minimal $\mathrm{H}$-bonding interactions. Indirect insights have also drawn from EPR data on $\mathrm{P}_{\mathrm{m}}$, where neither the $\mathrm{cu}^{\mathrm{II}}$ nor the Tyr radical signal has been observed, yet both are $S=1 / 2$ and proposed to be present. ${ }^{52}$ This has often been assumed to result from antiferromagnetic (AF) coupling between the $\mathrm{cu}^{\mathrm{II}}$ and the Tyr ${ }^{\bullet}{ }^{53-56}$ However, this could also result from rapid relaxation associated with the close proximity of three paramagnetic centers $\left(\mathrm{Fe}^{\mathrm{IV}}, \mathrm{cu}^{\mathrm{II}}, \mathrm{Tyr}^{*}\right)$, or strong ferromagnetic coupling between the $\mathrm{cu}^{\mathrm{II}}$ and $\mathrm{Tyr}^{\bullet}$ to yield a triplet. As the overall spin state in $\mathrm{P}_{\mathrm{m}}$ (and therefore $\mathrm{O}-\mathrm{O}$ cleavage) remains an open issue, our calculations explore $\mathrm{P}_{\mathrm{m}}$ derived on both the singlet and triplet spin surfaces ${ }^{57}$ Thus, we have evaluated the possible structures of $\mathrm{P}_{\mathrm{m}}$ with respect to the nature of the $\mathrm{Fe}^{\mathrm{IV}}=\mathrm{O}$ bond and the magnetic coupling in the active site. The results for each model are compiled in Table 2.

In the reaction coordinate for $\mathrm{O}-\mathrm{O}$ cleavage initiated by PT from Tyr (model $\{\mathbf{1 F}\}$ ), where a water molecule involved in PT bridges the Tyr and the $\mathrm{O}_{\mathrm{Fe}}$ atom, geometry optimization of the product structure yields $\{\mathbf{1 F}\}-\mathbf{P}_{\mathbf{M}}$ (Figure 12), in which the water is H-bonded to the $\mathrm{Fe}^{\mathrm{IV}}=\mathrm{O}$ (H-bonding to the neutral Tyr ${ }^{\bullet}$ is calculated to be $4 \mathrm{kcal} / \mathrm{mol}$ higher in energy). The water molecule in $\{\mathbf{1 F}\}-\mathbf{P}_{\mathbf{M}}$ has a calculated binding energy of $\Delta \mathrm{G}=-0.1 \mathrm{kcal} / \mathrm{mol}(\Delta \mathrm{H}=$ $-11.7 \mathrm{kcal} / \mathrm{mol}$ ). This structure has two $\mathrm{H}$-bonds to the $\mathrm{Fe}^{\mathrm{IV}}=\mathrm{O}$ (from the $\mathrm{cu}^{\mathrm{II}}-\mathrm{OH}$ and the $\mathrm{H}_{2} \mathrm{O}$ ), and an $\mathrm{Fe}-\mathrm{O}$ bond length of $1.642 \AA$. For a benchmark comparison, the heme fragment was also optimized separately, giving an $\mathrm{Fe}-\mathrm{O}$ of $1.633 \AA$. The longer $\mathrm{Fe}-\mathrm{O}$ in \{1F\}- $\mathbf{P}_{\mathbf{M}}$ suggests that the $\mathrm{H}$-bonds from cu-OH and $\mathrm{H}_{2} \mathrm{O}$ weaken the $\mathrm{Fe}-\mathrm{O}$ bond. Applying Badger's rule, an empirically-derived method for correlating bond length to stretching frequency, ${ }^{58}$ an elongation of the $\mathrm{Fe}-\mathrm{O}$ bond from $1.633 \AA$ in the isolated $\mathrm{Fe}^{\mathrm{IV}}=\mathrm{O}$ fragment to $1.642 \AA$ in $\{\mathbf{1 F}\}-\mathbf{P}_{\mathbf{M}}$ would correspond to a shift down in frequency of $16 \mathrm{~cm}^{-1}\left(\Delta v_{\mathrm{Fe}-\mathrm{O}}=\right.$ $\left.-16 \mathrm{~cm}^{-1}\right)$. Based on heavy-atom distances, the H-bond from water $\left(\mathrm{O}_{\mathrm{Fe}} \cdots \mathrm{O}_{\text {water }}=2.56 \AA\right)$ appears to be stronger than the $\mathrm{H}$-bond from the $\mathrm{cu}-\mathrm{OH}\left(\mathrm{O}_{\mathrm{Fe}} \cdots \mathrm{O}_{\mathrm{cu}}=2.92 \AA\right)$. The $\mathrm{Fe}$ and cu centers are predicted to be AF coupled $\left(\mathrm{J}=-5.0 \mathrm{~cm}^{-1}\right)$, while the cu-Tyr pair is predicted to be ferromagnetically coupled $\left(\mathrm{J}=+4.4 \mathrm{~cm}^{-1}\right)$. Therefore, the lowest energy electronic state is an overall singlet (local spins are shown in Figure 12, right), consistent with the lack of an EPR signal.

Since the $\mathrm{rR}$ data on $\mathrm{P}_{\mathrm{m}}$ suggest minimal $\mathrm{H}$-bonding to the $\mathrm{Fe}^{\mathrm{IV}}=\mathrm{O}$, the impact of two $\mathrm{H}$ bonds in $\{\mathbf{1 F}\}-\mathbf{P}_{\mathbf{m}}$ (predicted to lower the $\mathrm{v}_{\mathrm{Fe}-\mathrm{O}}$ by $\sim 16 \mathrm{~cm}^{-1}$ ) is greater than would be expected. Thus, we considered an alternative $\mathrm{P}_{\mathrm{m}}$ structure, $\{\mathbf{0}\}-\mathbf{P}_{\mathbf{m}}$, where the water molecule dissociates away from the active site (or is weakly bound to the Tyr ${ }^{\circ}$ and too far to interact with the $\mathrm{Fe}^{\mathrm{IV}}=\mathrm{O}$, as suggested by Sharma et al. ${ }^{20}$ ). In this case, only the $\mathrm{Cu}-\mathrm{OH}$ is $\mathrm{H}$-bonded to the $\mathrm{Fe}^{\mathrm{IV}}=\mathrm{O}$, and the optimized $\mathrm{Fe}-\mathrm{O}$ bond length is $1.634 \AA$. Based on a Badger's rule analysis, this would correspond to a $v_{\mathrm{Fe}-\mathrm{O}}$ that is only $\sim 2 \mathrm{~cm}^{-1}$ lower than an isolated $\mathrm{Fe}^{\mathrm{IV}}=\mathrm{O}$, suggesting that the $\mathrm{H}$-bond from the $\mathrm{Cu}-\mathrm{OH}$ has a minor impact on the $\mathrm{Fe}-\mathrm{O}$ bond 
strength. The magnetic coupling within the active site is similar to $\{\mathbf{1 F}\}-\mathbf{P}_{\mathbf{m}}$ : the $\mathrm{Fe}$ and $\mathrm{Cu}$ centers are AF coupled $\left(\mathrm{J}=-3.4 \mathrm{~cm}^{-1}\right)$, while the $\mathrm{Cu}-\mathrm{Tyr}{ }^{\bullet}$ pair is ferromagnetically coupled $\left(\mathrm{J}=+4.9 \mathrm{~cm}^{-1}\right)$, yielding an overall singlet ground state (Figure 12).

Evaluating the $\mathrm{P}_{\mathrm{M}}$ structure resulting from the reaction coordinate where a proton is shuttled directly to the $\mathrm{O}$ atom on $\mathrm{Cu}$ (as in model $\{\mathbf{1 C}\}$ ), $\mathrm{O}-\mathrm{O}$ cleavage leads to the product shown as $\{\mathbf{1 C}\}-\mathbf{P}_{\mathbf{m}}$ in Figure 12, which includes the water molecule near $\mathrm{Cu}$ involved in the initial proton transfer. The lowest energy structure has the water $\mathrm{H}$-bonding to the $\mathrm{O}$ of the $\mathrm{Cu}-\mathrm{OH}$, with the latter oriented toward the $\mathrm{Fe}^{\mathrm{IV}}=\mathrm{O}$. The binding energy for the water molecule in $\{\mathbf{1 C}\}-\mathbf{P}_{\mathbf{m}}$ (taken from bulk solution) is calculated to be favorable, giving a binding $\Delta \mathrm{G}$ of $-4.1 \mathrm{kcal} / \mathrm{mol}(\Delta \mathrm{H}=-15.5 \mathrm{kcal} / \mathrm{mol})$. The $\mathrm{Fe}-\mathrm{O}$ bond length is $1.635 \AA$, which is very close to the $1.633 \AA$ for the isolated $\mathrm{Fe}^{\mathrm{IV}}=\mathrm{O}$ (from Badger's rule, an elongation of $0.002 \AA$ corresponds to $\left.\Delta v_{\mathrm{Fe}-\mathrm{O}}=-4 \mathrm{~cm}^{-1}\right)$. Relative to $\{\mathbf{0}\}-\mathbf{P}_{\mathbf{m}}$, the $\mathrm{H}$-bond between the $\mathrm{Cu}^{\mathrm{II}}-\mathrm{OH}$ and the $\mathrm{Fe}^{\mathrm{IV}}=\mathrm{O}$ is slightly stronger $\left(\mathrm{O}_{\mathrm{Fe}} \cdots \mathrm{O}_{\mathrm{cu}}=2.74 \AA\right)$. Comparable to the possible PM structures above, in $\{\mathbf{1 C}\}-\mathbf{P}_{\mathbf{m}}$ the $\mathrm{Fe}^{\mathrm{IV}}$ and $\mathrm{Cu}^{\mathrm{II}}$ are $\mathrm{AF}$-coupled $\left(\mathrm{J}=-5.7 \mathrm{~cm}^{-1}\right)$, while the $\mathrm{Cu}^{\mathrm{II}}$ and $\mathrm{Tyr}^{\circ}$ are ferromagnetically coupled $\left(\mathrm{J}=+4.0 \mathrm{~cm}^{-1}\right)$, yielding an overall singlet ground state.

For comparison, we also evaluated a $\mathrm{P}_{\mathrm{m}}$ structure with a water ligand on the $\mathrm{Cu}$ (rather than hydroxo), which has been invoked in past computational studies. ${ }^{42}$ Optimizing such a product in our model generated the structure shown in Figure $\mathrm{S} 4$ (denoted $\left\{\mathbf{H}_{\mathbf{2}} \mathbf{O}\right\}-\mathbf{P}_{\mathbf{m}}$ ). In contrast to the three $\mathrm{P}_{\mathrm{m}}$ structures (with a $\mathrm{Cu}-\mathrm{OH}$ ) presented above, this model exhibits a much stronger $\mathrm{H}$-bond to the $\mathrm{Fe}^{\mathrm{IV}}=\mathrm{O}\left(\mathrm{O}_{\mathrm{Fe}} \cdot \mathrm{O}_{\mathrm{cu}}=2.44 \AA\right)$, giving a correspondingly longer $\mathrm{Fe}=\mathrm{O}$ bond $\left(1.657 \AA ; \Delta V_{\mathrm{Fe}-\mathrm{o}}=-41 \mathrm{~cm}^{-1}\right.$ versus the isolated $\mathrm{Fe}^{\mathrm{IV}}=\mathrm{O}$ by Badger's rule). In accordance with a stronger interaction between their oxo and aquo ligands, the AF coupling between $\mathrm{Fe}$ and $\mathrm{Cu}$ has increased to $\mathrm{J}=-14.7 \mathrm{~cm}^{-1}$. However, the coupling between $\mathrm{Cu}$ and Tyr has switched from ferro- to antiferromagnetic $\left(\mathrm{J}=-5.7 \mathrm{~cm}^{-1}\right)$, therefore favoring the overall triplet spin state.

To understand the nature of the magnetic coupling between the $\mathrm{Fe}^{\mathrm{IV}}=\mathrm{O} / \mathrm{Cu}^{\mathrm{II}}$ and $\mathrm{Cu}{ }^{\mathrm{II}} / \mathrm{Tyr}^{\bullet}$ centers, the molecular orbitals involved in their exchange interactions were examined, specifically the overlap of magnetic orbitals. Depicted in Figure 13A,B the antiferromagnetic coupling between $\mathrm{Fe}$ and $\mathrm{Cu}$ arises from a superexchange pathway

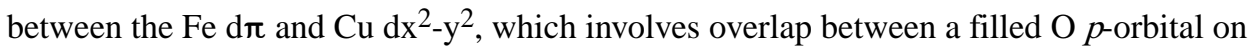
both of the oxo(Fe) and hydroxo $(\mathrm{Cu})$ ligands. This interaction results in the a-spin $\mathrm{Fe}_{\pi}(+$ $\mathrm{O}_{\mathrm{Fe}} p$ ) HOMO mixing into the $\mathrm{Cu} \mathrm{dx}{ }^{2}-\mathrm{y}^{2}\left(+\mathrm{O}_{\mathrm{cu}} p\right)$ LUMO, and the $\beta$-spin $\mathrm{Cu} \mathrm{dx}^{2}-\mathrm{y}^{2}\left(+\mathrm{O}_{\mathrm{cu}}\right.$ p) HOMO mixing into the $\mathrm{Fe} \mathrm{d}_{\pi}\left(+\mathrm{O}_{\mathrm{Fe}} p\right)$ LUMO. Therefore, the oxygenous ligands on $\mathrm{Fe}$ and $\mathrm{Cu}$ promote $\mathrm{AF}$ coupling between the metals by facilitating overlap of their magnetic orbitals.

In contrast, ferromagnetic coupling arises when magnetic orbitals involve orthogonal orbitals on a single atom center. Correlated to the magnetic coupling in $\mathrm{P}_{\mathrm{m}}$, this condition is observed in the calculations for the $\mathrm{Cu}-\mathrm{Tyr}^{*}$ pair in $\mathrm{P}_{\mathrm{m}}$ structures containing a $\mathrm{Cu}^{\mathrm{II}}-\mathrm{OH}$ species $\left(\{\mathbf{0}\}-\mathbf{P}_{\mathbf{m}},\{\mathbf{1 F}\}-\mathbf{P}_{\mathbf{m}}\right.$, and $\{\mathbf{1 C}\}-\mathbf{P}_{\mathbf{m}}$ ). While the $\mathrm{Cu} \mathrm{dx}{ }^{2}-\mathrm{y}^{2}$ LUMO has efficient overlap with the $\sigma$-donating orbital on His that is in the imidazole plane (Figure 13A), the Tyr LUMO mixes with a $\pi$ orbital on the His (Figure 13C, see also Section 3.3), which has lobes 
perpendicular to the imidazole plane. This orthogonal magnetic orbital electronic structure results in ferromagnetic coupling, depicted schematically in the left side of Figure 14.

As illustrated by the results for $\mathbf{\{} \mathbf{H 2 O}\}-\mathbf{P}_{\mathbf{M}}$ (Figure S3.3.1), changing the ligand on $\mathrm{Cu}$ from $\mathrm{OH}^{-}$to $\mathrm{H}_{2} \mathrm{O}$ also changes the ligand field, such that the $\mathrm{Cu} \mathrm{dx}{ }^{2}-\mathrm{y}^{2}$ LUMO now has His ( $\pi$ ) character. The interaction between the $\mathrm{Cu} \mathrm{dx}^{2}-\mathrm{y}^{2}$ and the His $(\pi)$ arises from a rotation of the former off the $\mathrm{Cu}-\mathrm{N}_{\mathrm{His}}$ axis, shown schematically on the right in Figure 14. Since the half-occupied orbitals on $\mathrm{Cu}^{\mathrm{II}}$ and $\mathrm{Tyr}^{\bullet}$ both have His $(\pi)$ character, the $\mathrm{Cu}^{\mathrm{II}}$ and $\mathrm{Tyr}{ }^{\bullet}$ are antiferromagnetically coupled in $\left\{\mathbf{H}_{2} \mathbf{O}\right\}-\mathbf{P}_{\mathbf{M}}$. This contrasts with the behavior for $\mathrm{Cu}^{\mathrm{II}}-\mathrm{OH}$ because the strong $\mathrm{OH}$ ligand dominates the ligand field (and therefore the orientation of the $\mathrm{Cudx} \mathrm{x}^{2}-\mathrm{y}^{2}$ orbital).

In summary, the above calculations evaluate possible PM models, particularly involving the $\mathrm{Fe}^{\mathrm{IV}}=\mathrm{O}$ bond and the magnetic couplings. Our results show that an $\mathrm{H}$-bond between the $\mathrm{Fe}^{\mathrm{IV}}=\mathrm{O}$ and a water molecule (either exogenous or as a ligand on $\mathrm{Cu}$ ) would significantly weaken the $\mathrm{Fe}-\mathrm{O}$ bond, inconsistent with existing $\mathrm{rR}$ data for $\mathrm{P}_{\mathrm{m}}$. However, an H-bond between the $\mathrm{Cu}^{\mathrm{II}}-\mathrm{OH}$ and the $\mathrm{Fe}^{\mathrm{IV}}=\mathrm{O}$ would have a minor impact on the $\mathrm{Fe}-\mathrm{O}$ bond (in agreement with the $\mathrm{rR}$ data), yet it would provide a pathway for exchange coupling between the $\mathrm{Fe}$ and $\mathrm{Cu}$, and may explain why a $\mathrm{Cu}^{\mathrm{II}} \mathrm{EPR}$ signal is not observed in $\mathrm{P}_{\mathrm{m}}$. The predicted ground state for $\mathrm{P}_{\mathrm{m}}$ is a singlet (for the lowest energy structure), arising from antiferromagetic coupling between the $\mathrm{Fe}^{\mathrm{IV}}=\mathrm{O}$ and $\mathrm{Cu}^{\mathrm{II}}-\mathrm{OH}$, and ferromagnetic coupling between the $\mathrm{Cu}^{\mathrm{II}}-\mathrm{OH}$ and $\mathrm{Tyr}^{\circ}$. Thus, the geometric and electronic structure described above for $\{\mathbf{0}\}-\mathbf{P}_{\mathbf{m}}$ (followed closely by $\{\mathbf{1 C}\}-\mathbf{P}_{\mathbf{m}}$, Figure 12) is consistent will all available experimental and computational data to-date.

\section{DISCUSSION}

While the HCO literature to-date has generally proposed that proton transfer from the active site Tyr precedes $\mathrm{O}-\mathrm{O}$ bond cleavage, and that the Tyr supplies the fourth electron required for $\mathrm{O}_{2}$ reduction, many details of the reaction mechanism remain unknown. This study evaluates: 1) how structural components of the active site (e.g. the cross-link and the farnesyl appendage on the heme) impact the mechanism and the barrier, 2) whether the proton transfer or $\mathrm{O}-\mathrm{O}$ cleavage is rate-limiting, 3) how and when the fourth electron (from Tyr) transfers, and 4) the geometric and electronic structure of the product $\left(\mathrm{P}_{\mathrm{m}}\right)$.

Drawing from the findings for $\mathrm{O}-\mathrm{O}$ cleavage in a synthetic heme-peroxo-Cu model system employing phenolic substrates, ${ }^{10}$ the results in Section 3.1 reveal how the active site in HCOs lowers the barrier for Proton-Initiated O-O cleavage (where PT is early in O-O cleavage) to approximately half that of the synthetic model ( $12 \mathrm{kcal} / \mathrm{mol} \mathrm{vs.} 25 \mathrm{kcal} / \mathrm{mol}$ ). Thus, while the synthetic model favors a mechanism involving PT after the barrier, for which the calculated $\Delta \mathrm{G}^{\ddagger}=16.5 \mathrm{kcal} / \mathrm{mol}$, HCOs perform O-O cleavage involving early PT with a calculated $\Delta \mathrm{G}^{\ddagger}$ of only $12 \mathrm{kcal} / \mathrm{mol}$ barrier. One primary reason for the lower barrier and different mechanism in HCOs relative to the previously studied synthetic model is the low pKa of the proton donor, Tyr. This derives from stabilization of the $\mathrm{Tyr}^{-}$anion by $\mathrm{H}-$ bonding to the hydroxyl group of the farnesyl side-chain and the $\mathrm{H}_{2} \mathrm{O}$ molecule involved in PT from Tyr to the bound $\mathrm{O}_{2}{ }^{2-}$, as well as the ortho-substitution to the cross-linked His- 
$\mathrm{Cu}^{\mathrm{II}} \cdot{ }^{35} \mathrm{~A}$ second factor in the low $\mathrm{O}-\mathrm{O}$ cleavage barrier is the separation between the $\mathrm{Tyr}^{-}$ anion and the $\mathrm{Fe}-\mathrm{OO}(\mathrm{H})-\mathrm{Cu}$ core, as $\mathrm{H}$-bonding to the $\mathrm{Cu}-\mathrm{OH}$ (as with an exogenous phenol in the synthetic model) would decrease the backbonding from the $\mathrm{Fe}$ into the $\mathrm{O} 2^{2-} \sigma^{*}$, raising the $\mathrm{O}-\mathrm{O}$ cleavage barrier. ${ }^{59}$

It has been proposed in the literature (and in this study) that proton transfer from Tyr may be mediated by one or two water molecules in the active site via a Grotthuss mechanism. 12,60-62 However, we have found that due to sterics within the active site (Section 3.1.2.1), the proton cannot transfer directly from the Tyr donor to the $\mathrm{O}_{\mathrm{cu}}$ acceptor without a high barrier, and must therefore transfer initially to the $\mathrm{O}_{\mathrm{Fe}}$ atom. Protonation of the $\mathrm{O}_{\mathrm{Fe}}$ yields a high-energy intermediate (calculated $\sim 13 \mathrm{kcal} / \mathrm{mol}$ above the bridging peroxo structure), which causes the proton transfer to have a higher barrier than $\mathrm{O}-\mathrm{O}$ cleavage, making the PT step rate-limiting. The KIE observed experimentally (1.4-1.9) is smaller than expected for PT between two sites with similar $\mathrm{H}^{+}$affinity (where the $\mathrm{H}^{+}$is in the middle in the transition state; thus KIEs are >5), while it is on the high side for secondary KIEs (a KIE of 1.4-1.9 would be expected for a change in $\mathrm{H}$-bonding). It is larger than would be expected for the O$\mathrm{O}(\mathrm{H})$ cleavage step, in which the $\mathrm{O}_{\mathrm{cu}}-\mathrm{H}$ bond is fully formed (the predicted KIE is $\leq 1$ ). Thus, the calculations indicate that the observed barrier for A to $\mathrm{P}_{\mathrm{M}}$ in HCOs involves proton transfer (where the $\mathrm{H}^{+}$is mostly transferred), which occurs early in $\mathrm{O}-\mathrm{O}$ bond cleavage.

In section 3.1.2.3, we considered the possibility of the $\mathrm{H}^{+}$transferring directly to the $\mathrm{O}_{\mathrm{cu}}$ atom from a donor other than the active site Tyr. Examples in the literature of Grotthussmediated PT over similar distances $(\sim 10 \AA)$ have reported barriers around $10 \mathrm{kcal} / \mathrm{mol}$ and KIEs of 1.4-3 (vide supra), in agreement with the data for A to $\mathrm{P}_{\mathrm{m}}$ in HCOs. While such a mechanism may therefore be active in HCOs, the literature has produced a few key experimental results that can be correlated to the DFT, supporting that the proton bound to the $\mathrm{O}_{\mathrm{cu}}$ in $\mathrm{P}_{\mathrm{m}}$ derives from the Tyr. First, recent crystallographic data by Rousseau et al. on the intermediate $\mathrm{P}_{\mathrm{r}}$ (which is similar to $\mathrm{P}_{\mathrm{m}}$ except the active site $\mathrm{Tyr}^{-}$is reduced; $\mathrm{P}_{\mathrm{r}}$ forms upon O-O cleavage from the fully reduced enzyme) have resolved a water molecule bound to the $\mathrm{Tyr}^{-}$, positioned in the region between the Tyr and the $\mathrm{O}_{\mathrm{Fe}}$ atom. ${ }^{24}$ The authors suggested that this water molecule may be stabilizing the $\mathrm{Tyr}^{-}$in $\mathrm{P}_{\mathrm{r}}$, identical to its role in OO cleavage inferred from our DFT calculations (vide supra). Second, the rate observed for A to $\mathrm{P}_{\mathrm{m}}$ is independent of $\mathrm{pH}$ from $6-9.5,{ }^{31}$ and varies minimally between HCOs from different organisms (which differ in some of the outer sphere residues). Since PT over a large distance $(\sim 10 \AA)$ would likely be impacted by changes in local electrostatics (different residues or protonation states), this suggests that the PT step occurs over a short distance that is highly conserved throughout $\mathrm{HCOs}$, and can operate effectively in a range of $\mathrm{pH}$ environments.

In addition to PT, the timing and means of ET from Tyr were examined to understand the role and mechanism of the tyrosinate electron transfer during the reaction. It was found that the electron transfers from $\mathrm{Tyr}^{-}$after the barrier to $\mathrm{O}-\mathrm{O}$ cleavage, and therefore does not contribute in the barrier. While ET from Tyr early in $\mathrm{O}-\mathrm{O}$ elongation would lower the $\mathrm{O}-\mathrm{O}$ cleavage barrier by increasing $\mathrm{O}_{2}{ }^{2-} \sigma^{*}$ occupation, this would require a lower potential $\mathrm{Tyr}^{-} / \mathrm{Tyr}^{\bullet}$ couple (i.e. a less stable $\mathrm{Tyr}^{-}$). Since the energetics of the PT step (which is rate- 
limiting and precedes $\mathrm{O}-\mathrm{O}$ elongation) are dictated by the thermodynamics of PT from Tyr to the peroxo $\mathrm{O}_{\mathrm{Fe}}$ atom, lowering the stability of the $\mathrm{Tyr}^{-}$anion would raise the PT barrier and consequently the overall reaction. Therefore, stabilizing the $\mathrm{Tyr}^{-}$is key for yielding a low barrier for $\mathrm{A}$ to $\mathrm{P}_{\mathrm{M}}$ in $\mathrm{HCOs}$, although it prevents the electron from transferring until after the barrier.

The above discussion describes how the $\mathrm{Cu}$-His-Tyr cross-link impacts the barrier by lowering the Tyr $\mathrm{pKa}$, preventing the $\mathrm{Tyr}^{-}$from interacting with the $\mathrm{Cu}-\mathrm{OH}$ during $\mathrm{O}-\mathrm{O}$ cleavage, and placing the Tyr close enough to the bound peroxo that the $\mathrm{H}^{+}$can be shuttled through a single water molecule. However, this unique structural motif is also responsible for enabling barrierless ET from the $\mathrm{Tyr}^{-}$to the peroxo $\sigma^{*}$ orbital. As shown in Section 3.1.2, the molecular orbitals involved in the superexchange pathway through the bridging His and $\mathrm{Cu}$ depend on the spin state, most notably the unoccupied $d$-orbital on $\mathrm{Cu}$. On the singlet surface, the electron propagates through this half-occupied $\mathrm{Cu} \mathrm{dx}{ }^{2}-\mathrm{y}^{2}$ orbital, while on the triplet surface it propagates as a hole transfer through the doubly occupied $\mathrm{Cu} \mathrm{d}_{\mathrm{yz}}$ orbital. Thus, the cross-link provides a means for efficient transfer of the fourth electron, regardless of the overall spin surface.

Taken together, the results above for $\mathrm{O}-\mathrm{O}$ cleavage in $\mathrm{HCO}$ provide a favored mechanism where a water molecule shuttles the proton from $\mathrm{Tyr}$ to the peroxo via the $\mathrm{O}_{\mathrm{Fe}}$ atom, with subsequent $\mathrm{O}-\mathrm{O}(\mathrm{H})$ cleavage yielding the product $\mathrm{P}_{\mathrm{M}}$. The water molecule involved in PT may be either $\mathrm{H}$-bonded to the $\mathrm{Fe}^{\mathrm{IV}}=\mathrm{O}$ or dissociated. The recent crystallographic data on $\mathrm{P}_{\mathrm{R}}$ provide critical comparison, which indicate that the water molecule in the active site is bound to the $\mathrm{Tyr}^{-}$and not the $\mathrm{Fe}^{\mathrm{IV}}=\mathrm{O} .{ }^{24}$ Since $\mathrm{rR}$ data have indicated that the $\mathrm{P}_{\mathrm{m}}$ and $\mathrm{P}_{\mathrm{r}}$ intermediates have identical $v(\mathrm{Fe}-\mathrm{O})$ stretches, ${ }^{49}$ these results suggest that the water molecule involved in $\mathrm{PT}$ is not $\mathrm{H}$-bonded to the $\mathrm{Fe}^{\mathrm{IV}}=\mathrm{O}$ in $\mathrm{P}_{\mathrm{m}}$. Thus, the geometric structure of $\mathrm{P}_{\mathrm{m}}$ in closest agreement with experimental data is that of $\{\mathbf{0}\}-\mathbf{P}_{\mathbf{m}}$ in Figure 12. Our calculations indicate that the electronic ground state is a singlet, arising from antiferromagnetic coupling between the $\mathrm{Fe}^{\mathrm{IV}}$ and $\mathrm{Cu}^{\mathrm{II}}$, and ferromagnetic coupling between the $\mathrm{Cu}^{\mathrm{II}}$ and Tyr', each on the order of $3-6 \mathrm{~cm}^{-1}$. This electronic structure is consistent with the $\mathrm{Cu}^{\mathrm{II}}$ and $\mathrm{Tyr}^{\bullet}$ being EPR-silent, yet it differs from models in the literature that have assumed these $S=1 / 2$ species are antiferromagnetically coupled. ${ }^{20,50,54,63}$ Experiments using variable-temperature, variable-field Magnetic Circular Dichroism (VTVH MCD) spectroscopy to probe this magnetic coupling are currently underway along with thier analysis that includes the effect of the zero field splitting of the $\mathrm{Fe}(\mathrm{IV})=\mathrm{O} \mathrm{S}=1$ on this exchange coupled three spin ground state. Applying these insights to the mechanism of $\mathrm{O}-\mathrm{O}$ cleavage, the overall singlet spin surface implies that the unobserved peroxo $\left(I_{P}\right)$ species responsible for accepting a proton from Tyr to initiate $\mathrm{O}-\mathrm{O}$ cleavage is a singlet (i.e. antiferromagnetically-coupled $\mathrm{Fe}^{\mathrm{III}}$ and $\mathrm{Cu}^{\mathrm{II}}$ ), and the electron from Tyr transfers to the O$\mathrm{O} \sigma^{*}$ via the cross-linked His and the magnetic (singly-occupied) orbital on $\mathrm{Cu}$ (which is tilted during ET to form the superexchange pathway).

While the combination of our DFT calculations and past experimental data offer insight into the mechanism of $\mathrm{O}-\mathrm{O}$ cleavage in $\mathrm{HCOs}$, as well as the geometric and electronic structure of $\mathrm{P}_{\mathrm{m}}$, our conclusions are limited by the experimental data available. Our understanding of the mechanism must draw heavily on the findings for a synthetic model that differs 
mechanistically from HCOs in both proton transfer and electron transfer. Our understanding of $\mathrm{P}_{\mathrm{m}}$ derives heavily from data ${ }^{24}$ on an intermediate $\left(\mathrm{P}_{\mathrm{r}}\right)$ that differs in the source of fourth electron (and therefore its electronic structure). Therefore, further studies involving synthetic models and spectroscopy on $\mathrm{P}_{\mathrm{m}}$ will be critical for advancing our understanding of how HCOs perform efficient $\mathrm{O}-\mathrm{O}$ bond cleavage, and how these enzymes use the resultant free energy gain to pump protons in 4 consecutive reductive steps after formation of $\mathrm{P}_{\mathrm{m}}$.

\section{CONCLUSION}

Applying past experimental and computational insights from synthetic models and enzyme intermediates, the results herein reveal how the active site in heme-copper oxidases enable an exceptionally low barrier for proton-initiated $\mathrm{O}-\mathrm{O}$ bond cleavage. It is shown that a water molecule in the active site can assist in proton transfer from the cross-linked tyrosine, and that multiple H-bonding interactions help to lower the tyrosine's $\mathrm{p} K_{a}$ by stabilizing the tyrosinate. Proton transfer to the bound $\mathrm{O}_{2}$ molecule precedes $\mathrm{O}-\mathrm{O}$ elongation and is rate limiting. Due to sterically restricted access to the $\mathrm{O}_{\mathrm{cu}}$ atom (which is protonated in the product $\mathrm{P}_{\mathrm{M}}$ ), the proton must either transfer initially to the $\mathrm{O}$ atom bound to $\mathrm{Fe}$ (a highenergy intermediate), or transfer over a $\sim 10 \AA$ distance to reach the $\mathrm{O}_{\mathrm{cu}}$ atom directly. While the distance between the $\mathrm{H}^{+}$donor (Tyr) and acceptor $\left(\mathrm{O}_{\mathrm{Cu}}\right)$ therefore causes a high barrier to PT, it is shown that this separation is critical for enabling a low barrier to $\mathrm{O}-\mathrm{O}$ cleavage, as it enhances backbonding from $\mathrm{Fe}$ into the $\mathrm{O}-\mathrm{O} \sigma^{*}$ orbital. Following the $\mathrm{O}-\mathrm{O}$ cleavage reaction coordinate to completion, we evaluate possible geometric and electronic structures of the product, intermediate $\mathrm{Pm}$. The geometric structure that is consistent with our computational results and all available experimental data contains a $\mathrm{Fe}^{\mathrm{IV}}=\mathrm{O}$ that is $\mathrm{H}$ bonded to the $\mathrm{Cu}^{\mathrm{II}}-\mathrm{OH}$, without water molecules interacting with the $\mathrm{Fe}^{\mathrm{IV}}=\mathrm{O}$. The ground state electronic structure of $\mathrm{P}_{\mathrm{M}}$ is an overall singlet: the $\mathrm{Fe}^{\mathrm{IV}}$ and $\mathrm{Cu}^{\mathrm{II}}$ are antiferromagnetically coupled through the $\mathrm{H}$-bond between the oxo $(\mathrm{Fe})$ and hydroxo $(\mathrm{Cu})$ ligands, while the $\mathrm{Cu}^{\mathrm{II}}$ and $\mathrm{Tyr}^{\bullet}$ are ferromagnetically coupled as their magnetic orbitals involve orthogonal orbitals on the cross-linked His residue. These findings provide critical insights into the mechanism by which $\mathrm{HCO}$ carry out efficient $\mathrm{O}_{2}$ reduction, and the nature of the $\mathrm{P}_{\mathrm{M}}$ intermediate that connects this reduction to the proton pumping function.

\section{Supplementary Material}

Refer to Web version on PubMed Central for supplementary material.

\section{ACKNOWLEDGMENTS}

This work was supported by the National Institutes of Health (DK031450).

\section{REFERENCES}

(1). Cracknell JA; Vincent KA; Armstrong FA Enzymes as Working or Inspirational Electrocatalysts for Fuel Cells and Electrolysis. Chem. Rev. 2008, 108, 2439-2461. [PubMed: 18620369]

(2). Wikström M; Krab K; Sharma V Oxygen Activation and Energy Conservation by Cytochrome C Oxidase. Chem. Rev. 2018, 118, 2469-2490. [PubMed: 29350917]

(3). Kaila VRI; Verkhovsky MI; Wikstrom MAR Proton-Coupled Electron Transfer in Cytochrome Oxidase. Chem. Rev. 2010, 110, 7062-7081. [PubMed: 21053971] 
(4). Hirata K; Shinzawa-Itoh K; Yano N; Takemura S; Kato K; Hatanaka M; Muramoto K; Kawahara T; Tsukihara T; Yamashita E; Kensuke T; Uene G; Hikima T; Murakami H; Inubushi Y; Yabashi M; Ishikawa T; Yamamoto M; Ogura T; Sugimoto H; Shen J-R; Yoshikawa S; Ago H. Determination of Damage-Free Crystal Structure of an X-Ray-Sensitive Protein Using an XFEL. Nat. Methods 2014, 11, 734-736. [PubMed: 24813624]

(5). Solomon EI; Heppner DE; Johnston EM; Ginsbach JW; Cirera J; Qayyum M; Kieber-Emmons MT; Kjaergaard CH; Hadt RG; Tian L Copper Active Sites in Biology. Chem. Rev.2014, 114, 3659-3853. [PubMed: 24588098]

(6). Han S; Ching YC; Rousseau DL Ferryl and Hydroxy Intermediates in the Reaction of Oxygen with Reduced Cytochrome C Oxidase. Nature 1990, 348, 89-90. [PubMed: 2172834]

(7). Varotsis C; Woodruff WH; Babcock GT; Woodruffi H; Babcock T Direct Detection of a Dioxygen Adduct of Cytochrome A3 in the Mixed Valence Cytochrome Oxidase/Dioxygen Reaction. J. Biol. Chem. 1990, 265, 11131-11136. [PubMed: 2162832]

(8). Gennis RB Multiple Proton-Conducting Pathways in Cytochrome Oxidase and a Proposed Role for the Active-Site Tyrosine. Biochim. Biophys. Acta, Bioenerg. 1998, 1365, 241-248.

(9). Poiana F; von Ballmoos C; Gonska; Blomberg MRÄ; Adelroth P; Brzezinski P Splitting of the OO Bond at the Heme-Copper Catalytic Site of Respiratory Oxidases. Science Advances 2017, 3, e1700279.

(10). Schaefer AW; Kieber-Emmons MT; Adam SM; Karlin KD; Solomon EI Phenol-Induced O-O Bond Cleavage in a Low-Spin Heme-Peroxo-Copper Complex: Implications for O2 Reduction in Heme-Copper Oxidases. J. Am. Chem. Soc. 2017, 139, 7958-7973. [PubMed: 28521498]

(11). Han Du W-G; Noodleman L Broken Symmetry DFT Calculations/Analysis for Oxidized and Reduced Dinuclear Center in Cytochrome C Oxidase: Relating Structures, Protonation States, Energies, and Mössbauer Properties in Ba3 Thermus Thermophilus. Inorg. Chem. 2015, 54, 7272-7290. [PubMed: 26192749]

(12). Blomberg MRA; Siegbahn PEM; Wikstrom MAR Metal-Bridging Mechanism for O-O Bond Cleavage in Cytochrome C Oxidase. Inorg. Chem. 2003, 42, 5231-5243. [PubMed: 12924894]

(13). Du W-GH; Noodleman L Density Functional Study for the Bridged Dinuclear Center Based on a High-Resolution X-Ray Crystal Structure of Ba3 Cytochrome C Oxidase From Thermus Thermophilus. Inorg. Chem. 2013, 52, 14072-14088. [PubMed: 24262070]

(14). Aoyama H; Muramoto K; Shinzawa-Itoh K; Hirata K; Yamashita E; Tsukihara T; Ogura T; Yoshikawa S A Peroxide Bridge Between Fe and $\mathrm{Cu}$ Ions in the O2 Reduction Site of Fully Oxidized Cytochrome C Oxidase Could Suppress the Proton Pump. Proc. Natl. Acad. Sci. U. S. A. 2009, 106, 2165-2169. [PubMed: 19164527]

(15). Adam SM; Wijeratne GB; Rogler PJ; Diaz DE; Quist DA; Liu JJ; Karlin KD Synthetic Fe/Cu Complexes: Toward Understanding Heme-Copper Oxidase Structure and Function. Chem. Rev. 2018, 118, 10840-11022. [PubMed: 30372042]

(16). Gorbikova EA; Belevich NP; Wikstrom MAR; Verkhovsky MI Time-Resolved ATR-FTIR Spectroscopy of the Oxygen Reaction in the D124N Mutant of Cytochrome cOxidase From Paracoccus Denitrificans $\dagger$. Biochemistry 2007, 46, 13141-13148. [PubMed: 17949011]

(17). Sharma V; Wikström M The Role of the K-Channel and the Active-Site Tyrosine in the Catalytic Mechanism of Cytochrome C Oxidase. Biochim. Biophys. Acta. 2016, 1857, 1111-1115. [PubMed: 26898520]

(18). Gorbikova EA; Wikström M; Verkhovsky MI The Protonation State of the Cross-Linked Tyrosine During the Catalytic Cycle of Cytochrome C Oxidase. J. Biol. Chem. 2008, 283, 34907-34912. [PubMed: 18931371]

(19). Qin L; Liu J; Mills DA; Proshlyakov DA; Hiser C; Ferguson-Miller S Redox-Dependent Conformational Changes in Cytochrome C Oxidase Suggest a Gating Mechanism for Proton Uptake. Biochemistry 2009, 48, 5121-5130. [PubMed: 19397279]

(20). Sharma V; Wikstrom M; Kaila VRI Stabilization of the Peroxy Intermediate in the Oxygen Splitting Reaction of Cytochrome Cbb(3). Biochim. Biophys. Acta. 2011, 1807, 813-818. [PubMed: 21315685]

(21). Han Du W-G; Götz AW; Yang L; Walker RC; Noodleman L A Broken-Symmetry Density Functional Study of Structures, Energies, and Protonation States Along the Catalytic O-O Bond 
Cleavage Pathway in Ba3 Cytochrome C Oxidase From Thermus Thermophilus. Phys. Chem. Chem. Phys. 2016, 18, 21162-21171. [PubMed: 27094074]

(22). Wiertz FGM; Richter O-MH; Ludwig B; de Vries S Kinetic Resolution of a Tryptophan-Radical Intermediate in the Reaction Cycle of Paracoccus Denitrificans Cytochrome C Oxidase. J. Biol. Chem. 2007, 282, 31580-31591. [PubMed: 17761680]

(23). Yu MA; Egawa T; Shinzawa-Itoh K; Yoshikawa S; Yeh S-R; Rousseau DL; Gerfen GJ Radical Formation in Cytochrome C Oxidase. Biochim. Biophys. Acta. 2011, 1807, 1295-1304. [PubMed: 21718686]

(24). Ishigami I; Lewis-Ballester A; Echelmeier A; Brehm G; Zatsepin NA; Grant TD; Coe JD; Lisova S; Nelson G; Zhang S; Dobson ZF; Boutet S; Sierra RG; Batyuk A; Fromme P; Fromme R; Spence JCH; Ros A; Yeh S-R; Rousseau DL Snapshot of an Oxygen Intermediate in the Catalytic Reaction of Cytochrome C Oxidase. Proc. Natl. Acad. Sci. U. S. A. 2019, 116, 3572-3577. [PubMed: 30808749]

(25). Oda K; Ogura T; Appelman EH; Yoshikawa S The Intrinsic Stability of the Second Intermediate Following the Dioxygen-Bound Form in the $\mathrm{O} 2$ Reduction by Cytochrome C Oxidase. FEBS Lett 2004, 570, 161-165. [PubMed: 15251458]

(26). Pinakoulaki E; Daskalakis V; Ohta T; Richter O-MH; Budiman K; Kitagawa T; Ludwig B; Varotsis C The Protein Effect in the Structure of Two Ferryl-Oxo Intermediates at the Same Oxidation Level in the Heme Copper Binuclear Center of Cytochrome C Oxidase. J. Biol. Chem. 2013, 288, 20261-20266. [PubMed: 23723073]

(27). Morgan JE; Verkhovsky MI; Palmer G; Wikström M Role of the PR Intermediate in the Reaction of Cytochrome C Oxidase with O2. Biochemistry 2001, 40, 6882-6892. [PubMed: 11389603]

(28). Yamaguchi K; Jensen F; Dorigo A; Houk KN A Spin Correction Procedure for Unrestricted Hartree-Fock and M01ler-Plesset Wavefunctions for Singlet Diradicals and Polyradicals. Chemical Physics Letters 1988, 149, 537-542.

(29). Kieber-Emmons MT Lumo, Version 1.0.3; Salt Lake City, UT, 2014.

(30). Kim E; Kamaraj K; Galliker B; Rubie ND; Moenne-Loccoz P; Kaderli S; Zuberb u hler A. D.; Karlin KD Dioxygen Reactivity of Copper and Heme-Copper Complexes Possessing an Imidazole-Phenol Cross-Link. Inorg. Chem. 2005, 44, 1238-1247. [PubMed: 15732964]

(31). Karpefors M; Ädelroth P; Namslauer A; Zhen Y; Brzezinski P Formation of the "Peroxy" Intermediate in Cytochrome cOxidase Is Associated with Internal Proton/Hydrogen Transfer. Biochemistry 2000, 39, 14664-14669. [PubMed: 11087423]

(32). Karpefors M; Ädelroth P; Aagaard A; Smirnova IA; Brzezinski P The Deuterium Isotope Effect as a Tool to Investigate Enzyme Catalysis: Proton-Transfer Control Mechanisms in Cytochrome C Oxidase. Israel Journal of Chemistry 1999, 39, 427-437.

(33). Kaila VRI; Hummer G Energetics and Dynamics of Proton Transfer Reactions Along Short Water Wires. Phys. Chem. Chem. Phys. 2011, 13, 13207-13215. [PubMed: 21701719]

(34). Agmon N The Grotthuss Mechanism. Chemical Physics Letters 1995, 244, 456-462.

(35). McCauley KM; Vrtis JM; Dupont J Insights Into the Functional Role of the Tyrosine-Histidine Linkage in Cytochrome C Oxidase. J. Am. Chem. Soc. 2000, 122, 2403-2404.

(36). Pratt Derek A; Russell P Pesavento A.; van der Donk WA Model Studies of the HistidineTyrosine Cross-Link in Cytochrome C Oxidase Reveal the Flexible Substituent Effect of the Imidazole Moiety. Org. Lett. 2005, 7, 2735-2738. [PubMed: 15957934]

(37). Cappuccio JA; Ayala I; Elliott GI; Szundi I; Lewis J; Konopelski JP; Barry BA; Einarsdottir O Modeling the Active Site of Cytochrome Oxidase: Synthesis and Characterization of a CrossLinked Histidine-Phenol. J. Am. Chem. Soc. 2002, 124, 1750-1760. [PubMed: 11853453]

(38). An analogous $\mathrm{H}$-bonding interaction in $\mathrm{CcO}$ would involve a water molecule in the active site $\mathrm{H}$ bonding to the $\mathrm{Cu}-\mathrm{OH}$ during $\mathrm{O}-\mathrm{O}$ cleavage (i.e. from a water in the region specified for model $\{1 \mathrm{C}\}$, highlighted in blue in Figure 6), in which case the calculated barrier for $\mathrm{H} \rightarrow \mathrm{TSpi}$ increases by $\sim 5 \mathrm{kcal} / \mathrm{mol}$.

(39). Sharma V; Enkavi G; Vattulainen I; Róg T; Wikström M Proton-Coupled Electron Transfer and the Role of Water Molecules in Proton Pumping by Cytochrome C Oxidase. Proc. Natl. Acad. Sci. U. S. A. 2015, 112, 2040-2045. [PubMed: 25646428] 
(40). Petrik ID; Davydov R; Ross M; Zhao X; Hoffman B; Lu Y Spectroscopic and Crystallographic Evidence for the Role of a Water-Containing H-Bond Network in Oxidase Activity of an Engineered Myoglobin. J. Am. Chem. Soc. 2016, 138, 1134-1137. [PubMed: 26716352]

(41). Fee JA; Case DA; Noodleman L Toward a Chemical Mechanism of Proton Pumping by the BType Cytochrome C Oxidases: Application of Density Functional Theory to Cytochrome Ba3 of Thermus Thermophilus. J. Am. Chem. Soc. 2008, 130, 15002-15021. [PubMed: 18928258]

(42). Noodleman L; Han Du W-G; Fee JA; Götz AW; Walker RC Linking Chemical Electron-Proton Transfer to Proton Pumping in Cytochrome C Oxidase: Broken-Symmetry DFT Exploration of Intermediates Along the Catalytic Reaction Pathway of the Iron-Copper Dinuclear Complex. Inorg. Chem. 2014, 53, 6458-6472. [PubMed: 24960612]

(43). Grancha T; Ferrando-Soria J; Cano J; Amorós P; Seoane B; Gascon J; Bazaga-García M; Losilla ER; Cabeza A; Armentano D; Pardo E Insights Into the Dynamics of Grotthuss Mechanism in a Proton-Conducting Chiral bioMOF. Chemistry of Materials 2016, 28, 4608-4615.

(44). Schulten Z; Schulten K Proton Conduction Through Proteins: an Overview of Theoretical Principles and Applications. Meth. Enzymol. 1986, 127, 419-438. [PubMed: 3016464]

(45). Chow MS; Liu LV; Solomon EI Further Insights Into the Mechanism of the Reaction of Activated Bleomycin with DNA. Proc. Natl. Acad. Sci. U. S. A. 2008, 105, 13241-13245. [PubMed: 18757754]

(46). Wong SD; Bell CB; Liu LV; Kwak Y; England J; Alp EE; Zhao J; Que L; Solomon EI Nuclear Resonance Vibrational Spectroscopy on the $\mathrm{Fe}(\mathrm{IV})=\mathrm{O} \mathrm{S}=2$ Non-Heme Site in TMG3tren: Experimentally Calibrated Insights Into Reactivity. Angew. Chem., Int. Ed. 2011, 50, 3215-3218.

(47). Amdursky N; Wang X; Meredith P; Bradley DDC; Stevens MM Long-Range Proton Conduction Across Free-Standing Serum Albumin Mats. Adv. Mater. Weinheim 2016, 28, 2692-2698. [PubMed: 26840865]

(48). Ordinario DD; Phan L; Walkup WG IV; Jocson J-M; Karshalev E; Hüsken N; Gorodetsky AA Bulk Protonic Conductivity in a Cephalopod Structural Protein. Nat. Chem. 2014, 6, 596-602. [PubMed: 24950329]

(49). Pinakoulaki E; Pfitzner U; Ludwig B; Varotsis C Direct Detection of $\mathrm{Fe}(\mathrm{IV})=\mathrm{O}$ Intermediates in the Cytochrome Aa3 Oxidase From Paracoccus Denitrificans/H2O2 Reaction. J. Biol. Chem. 2003, 278, 18761-18766. [PubMed: 12637529]

(50). Blomberg MRA Mechanism of Oxygen Reduction in Cytochrome C Oxidase and the Role of the Active Site Tyrosine. Biochemistry 2016, 55, 489-500. [PubMed: 26690322]

(51). Sharma V; Karlin KD; Wikstrom M Computational Study of the Activated OH State in the Catalytic Mechanism of Cytochrome C Oxidase. Proc. Natl. Acad. Sci. U. S. A. 2013, 110, 16844-16849. [PubMed: 24082138]

(52). Blair DF; Witt SN; Chan SI Mechanism of Cytochrome C Oxidase-Catalyzed Dioxygen Reduction at Low Temperatures. Evidence for Two Intermediates at the Three-Electron Level and Entropic Promotion of the Bond-Breaking Step. J. Am. Chem. Soc. 1985, 107, 7389-7399.

(53). Fabian M; Palmer G The Interaction of Cytochrome Oxidase with Hydrogen Peroxide: the Relationship of Compounds P and F. Biochemistry 1995, 34, 13802-13810. [PubMed: 7577973]

(54). Kieber-Emmons MT; Li Y; Halime Z; Karlin KD; Solomon EI Electronic Structure of a LowSpin Heme/Cu Peroxide Complex: Spin-State and Spin-Topology Contributions to Reactivity. Inorg. Chem. 2011, 50, 11777-11786. [PubMed: 22007669]

(55). Rich PR; Rigby SEJ; Heathcote P Radicals Associated with the Catalytic Intermediates of Bovine Cytochrome C Oxidase. Biochim. Biophys. Acta, Bioenerg. 2002, 1554, 137-146.

(56). Iwaki M; Puustinen A; Wikström M; Rich PR Structural and Chemical Changes of the P(M) Intermediate of Paracoccus Denitrificans Cytochrome C Oxidase Revealed by IR Spectroscopy with Labeled Tyrosines and Histidine. Biochemistry 2006, 45, 10873-10885. [PubMed: 16953573]

(57). Yoshioka Y; Satoh H; Mitani M Theoretical Study on Electronic Structures of FeOO, FeOOH, $\mathrm{FeO}(\mathrm{H} 2 \mathrm{O})$, and $\mathrm{FeO}$ in Hemes: as Intermediate Models of Dioxygen Reduction in Cytochrome C Oxidase. J. Inorg. Biochem. 2007, 101, 1410-1427. [PubMed: 17662458] 
(58). Green MT Application of Badger's Rule to Heme and Non-Heme Iron-Oxygen Bonds: an Examination of Ferryl Protonation States. J. Am. Chem. Soc. 2006, 128, 1902-1906. [PubMed: 16464091]

(59). Lehnert N; Ho RY; Que L; Solomon EI Electronic Structure of High-Spin Iron(III)-Alkylperoxo Complexes and Its Relation to Low-Spin Analogues: Reaction Coordinate of O-O Bond Homolysis. J. Am. Chem. Soc. 2001, 123, 12802-12816. [PubMed: 11749538]

(60). Ehudin MA; Schaefer AW; Adam SM; Quist DA; Diaz DE; Tang JA; Solomon EI; Karlin KD Influence of Intramolecular Secondary Sphere Hydrogen-Bonding Interactions on Cytochrome Coxidase Inspired Low-Spin Heme-Peroxo-Copper Complexes. Chem. Sci. 2019, 10, 28932905. [PubMed: 30996867]

(61). Yoshioka Y; Mitani M B3LYP Study on Reduction Mechanisms From O2 to H2O at the Catalytic Sites of Fully Reduced and Mixed-Valence Bovine Cytochrome c Oxidases. Bioinorg. Chem. Appl. 2010, 2010, 1-18.

(62). Yoshikawa S; Muramoto K; Shinzawa-Itoh K; Mochizuki M Structural Studies on Bovine Heart Cytochrome C Oxidase. Biochim. Biophys. Acta. 2012, 1817, 579-589. [PubMed: 22236806]

(63). Fabian M; Palmer G Redox State of Peroxy and Ferryl Intermediates in Cytochrome C Oxidase Catalysis. Biochemistry 1999, 38, 6270-6275. [PubMed: 10320356] 


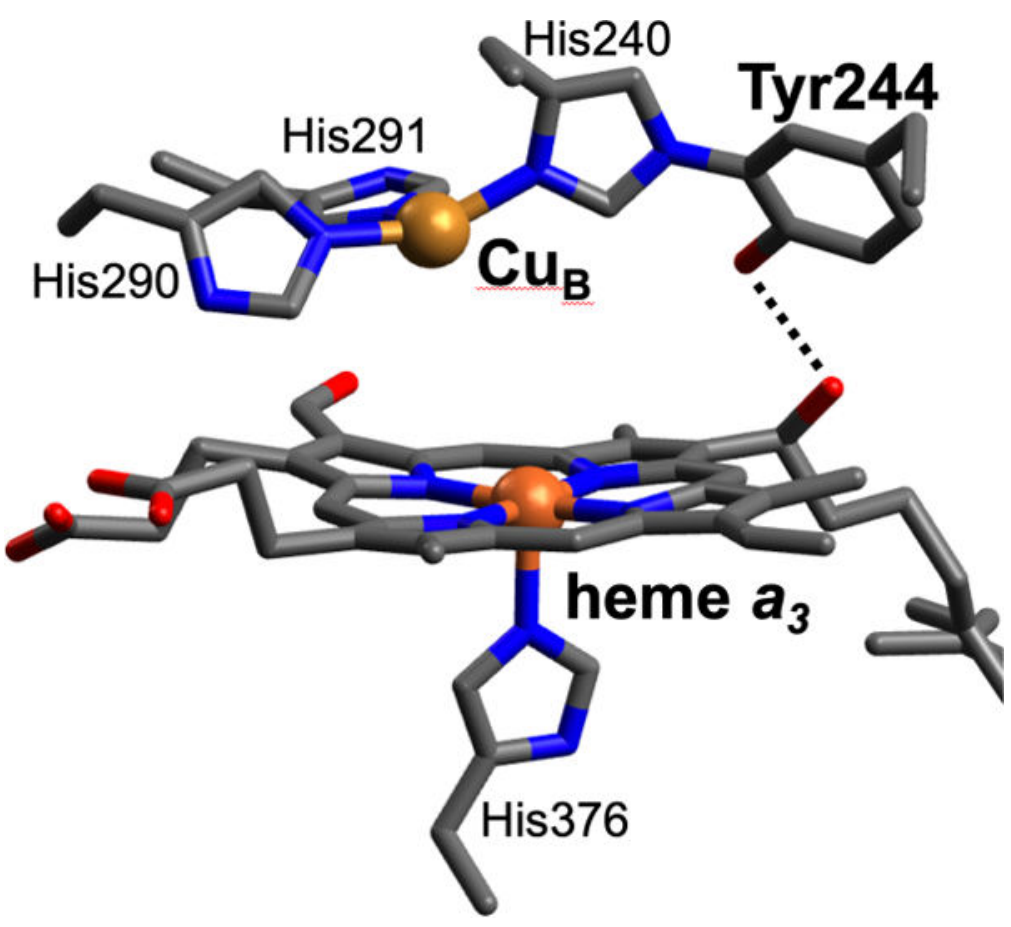

Figure 1.

Structure of the heme/Cu active site in bovine $\mathrm{CcO}$ (PDB 3WG7). 


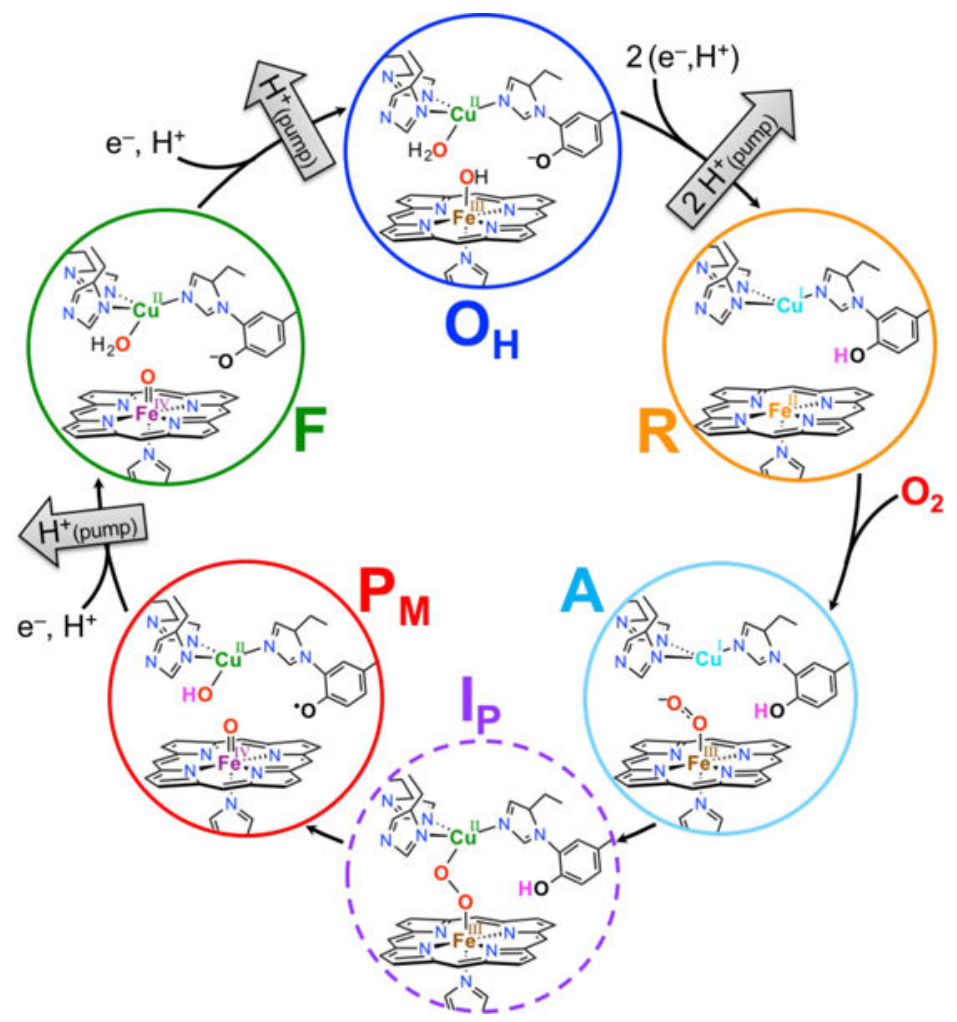

Figure 2.

Current consensus mechanism in HCOs, including the proposed involvement of a peroxo intermediate ( $\mathbf{I}_{\mathbf{p}}$ ) prior to $\mathrm{O}-\mathrm{O}$ cleavage. 


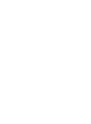

$\mathrm{H} 291$

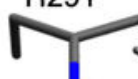
$\mathrm{H} 290$

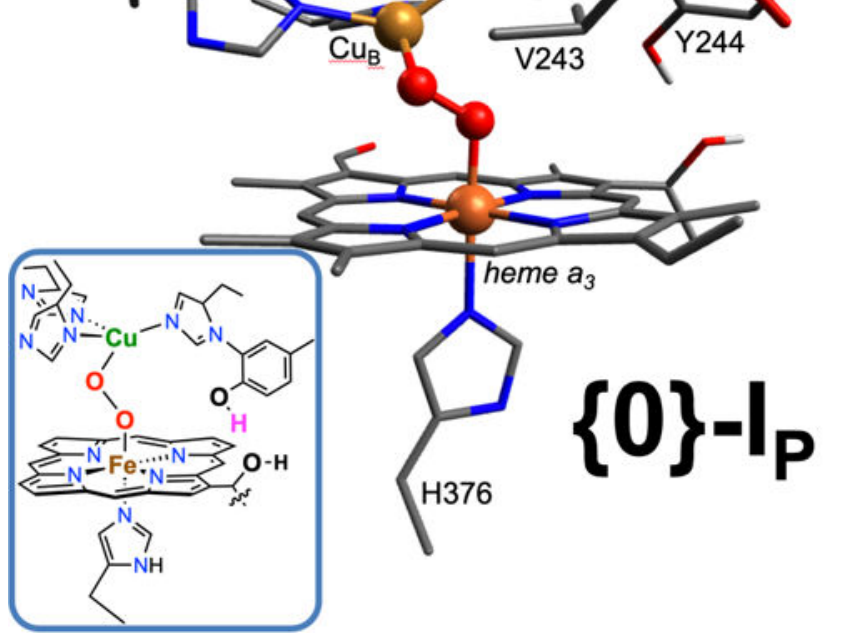

B
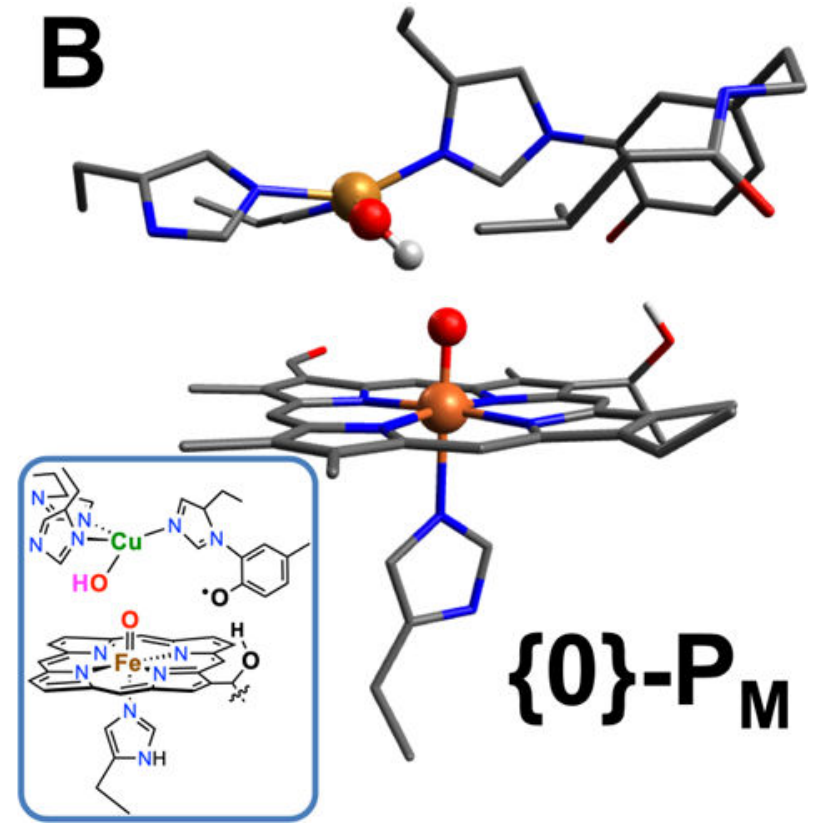

Figure 3.

DFT-optimized structures constructed from the crystal structure of the bovine $\mathrm{CcO}$ active site (3WG7) without water molecules included (denoted model $\{\mathbf{0}\}$ ), showing the A) peroxo (IP), and B) ferryl $/ \mathrm{Y}^{*}\left(\mathrm{P}_{\mathrm{m}}\right)$ species (i.e. the reactant and product structures in $\mathrm{O}-\mathrm{O}$ cleavage). 

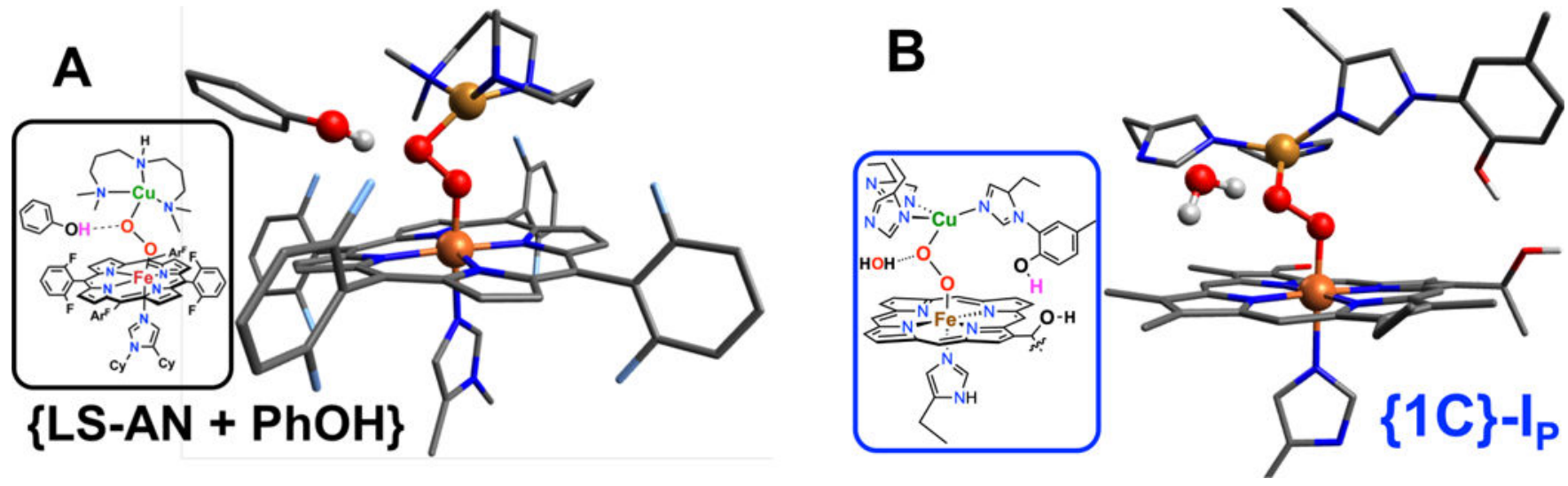

Figure 4.

DFT-optimized structures for the reactant in the H-Bond Assisted mechanism in LS-AN (A) and $\mathrm{CcO}(\mathrm{B})$, where the $\mathrm{H}$-bond donor is bound to the Ocu atom of the bridging peroxo ligand. Note that Val243 in $\{1 \mathrm{C}\}-\mathrm{I}_{\mathrm{p}}$ has been removed for visual clarity. 


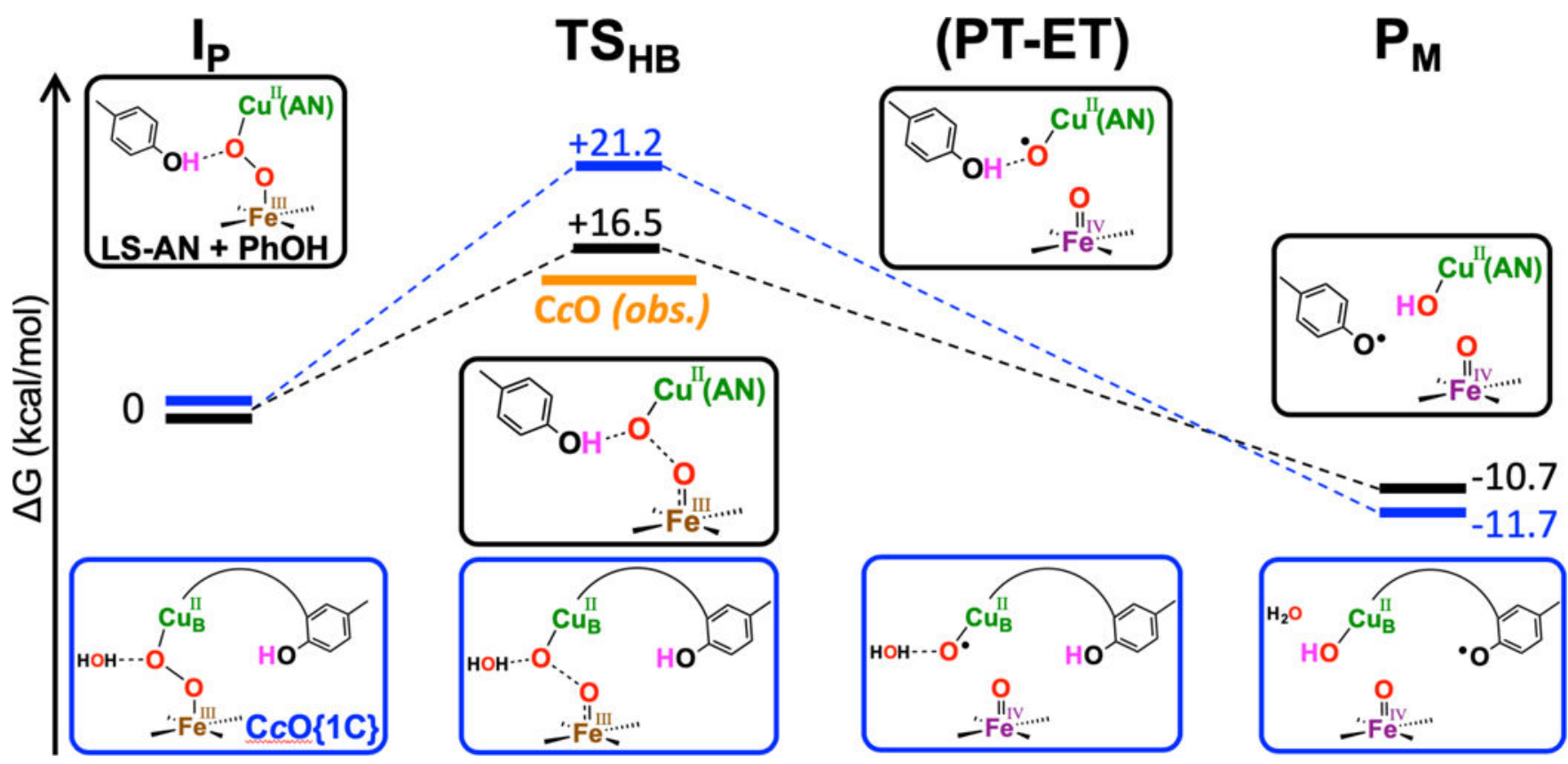

Figure 5.

Calculated energetics $(\Delta \mathrm{G}$, in $\mathrm{kcal} / \mathrm{mol})$ in the reaction coordinate for the $\mathrm{H}$-Bond Assisted mechanism in LS-AN (black) and $\mathrm{CcO}$ (blue). The experimental barrier in $\mathrm{CcO}\left(\Delta \mathrm{G}^{\ddagger}<12.4\right.$ $\mathrm{kcal} / \mathrm{mol}$ ) is given for reference. 


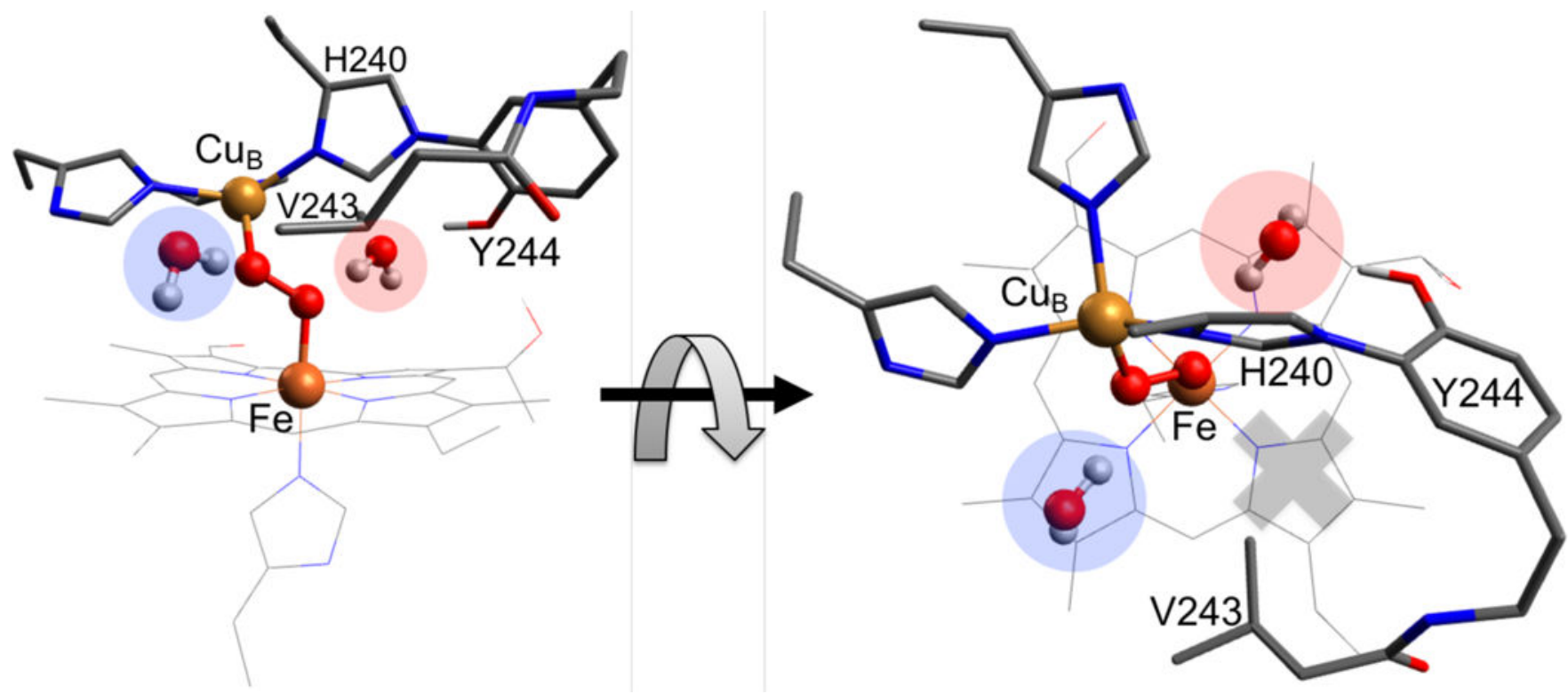

Figure 6.

Side (left) and top-down (right) views of the active site, illustrating the two possible ways in which a water molecule may access the bound $\mathrm{O}_{2}$. The blue circle marks the water location in model $\{\mathbf{1 C}\}$, and the red circle marks the location occupied in model $\{\mathbf{1 F}\}$ (note each contains only one $\mathrm{H}_{2} \mathrm{O}$ molecule). The gray $\mathrm{X}$ in the left figure indicates the region that would provide a direct path from Tyr to the $\mathrm{O}_{\mathrm{cu}}$ atom, which is hindered by the His 240 and Val243 residues. 


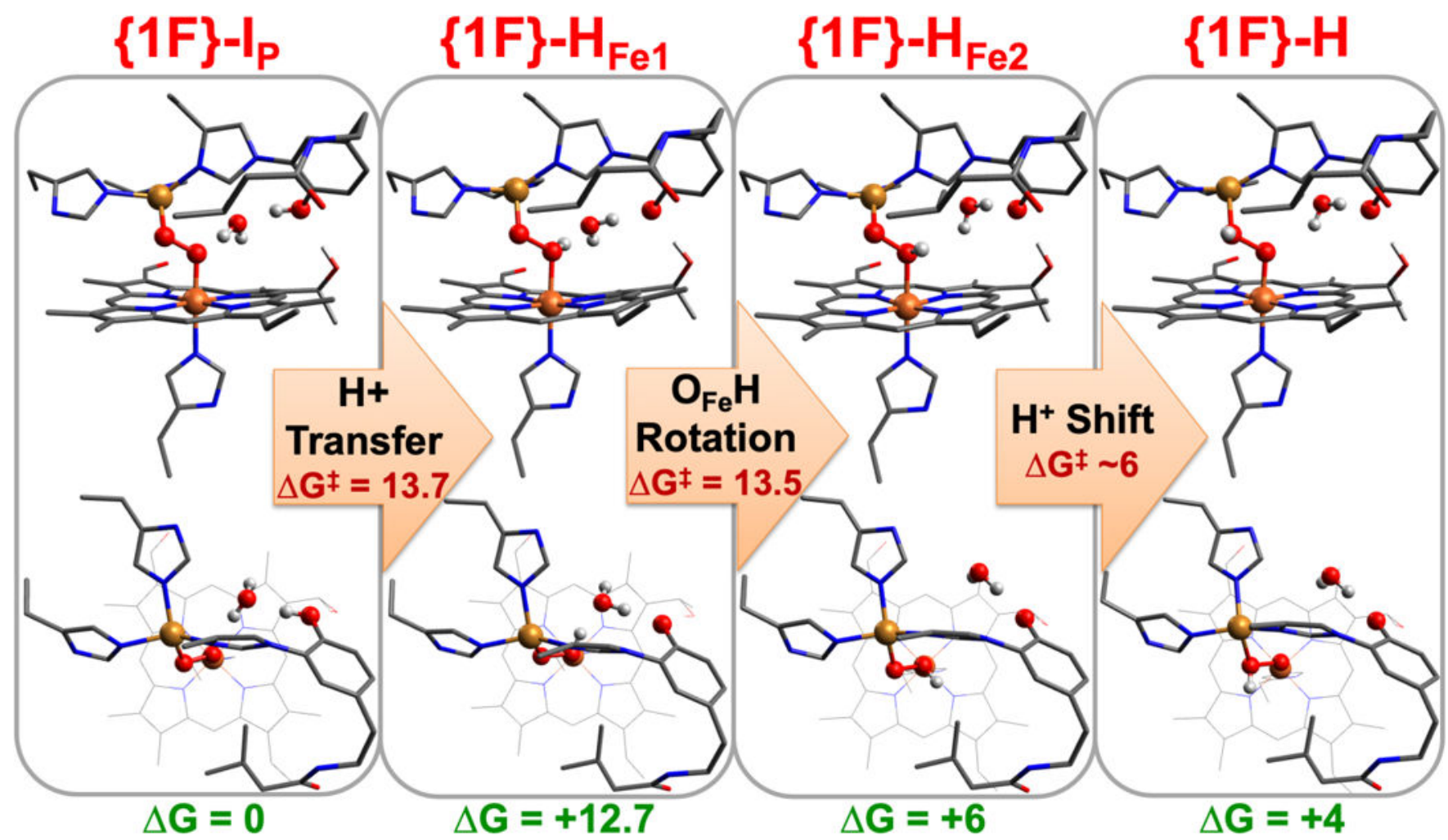

Figure 7.

Process of $\mathrm{H}^{+}$transfer from the active site Tyr to the peroxo $\mathrm{O}_{\mathrm{cu}}$ atom, mediated by the interstitial water molecule in model $\{\mathbf{I F}\}$. The upper half of each panel shows a side-on view of the active site, while the lower half shows a top-down view (down the $\mathrm{O}_{\mathrm{Fe}}-\mathrm{Fe}$ bond). Calculated $\Delta \mathrm{G}$ values (in $\mathrm{kcal} / \mathrm{mol}$, relative to $\{\mathbf{1 F}\}-\mathbf{I}_{\mathbf{p}}$ ) for each optimized species are shown in green, and barriers for each step given in red. 


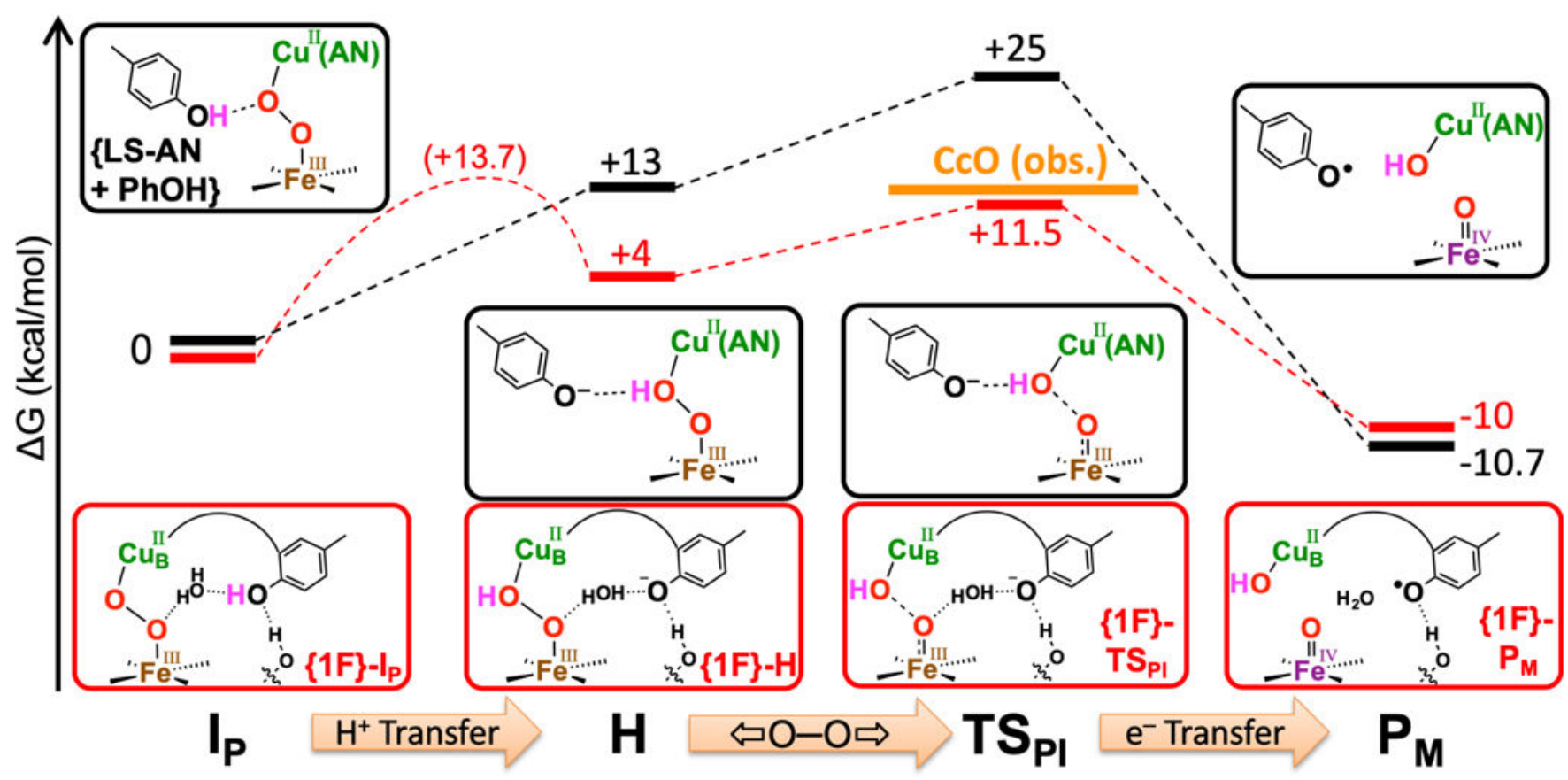

Figure 8.

Calculated energetics $(\Delta \mathrm{G}$, in $\mathrm{kcal} / \mathrm{mol})$ in the reaction coordinate for the Proton-Initiated mechanism in the synthetic model $\{\mathrm{LS}-\mathrm{AN}+\mathrm{PhOH}\}$ (black) and the $\mathrm{CcO}$ model $\{\mathbf{1 F}\}$ (red), which has a water molecule bridging the Tyr and $\mathrm{O}_{\mathrm{Fe}}$ atom of the peroxo. The $\Delta \mathrm{G}^{\ddagger}<12.4$ $\mathrm{kcal} / \mathrm{mol}$ experimental barrier in $\mathrm{CcO}$ is shown for reference. 


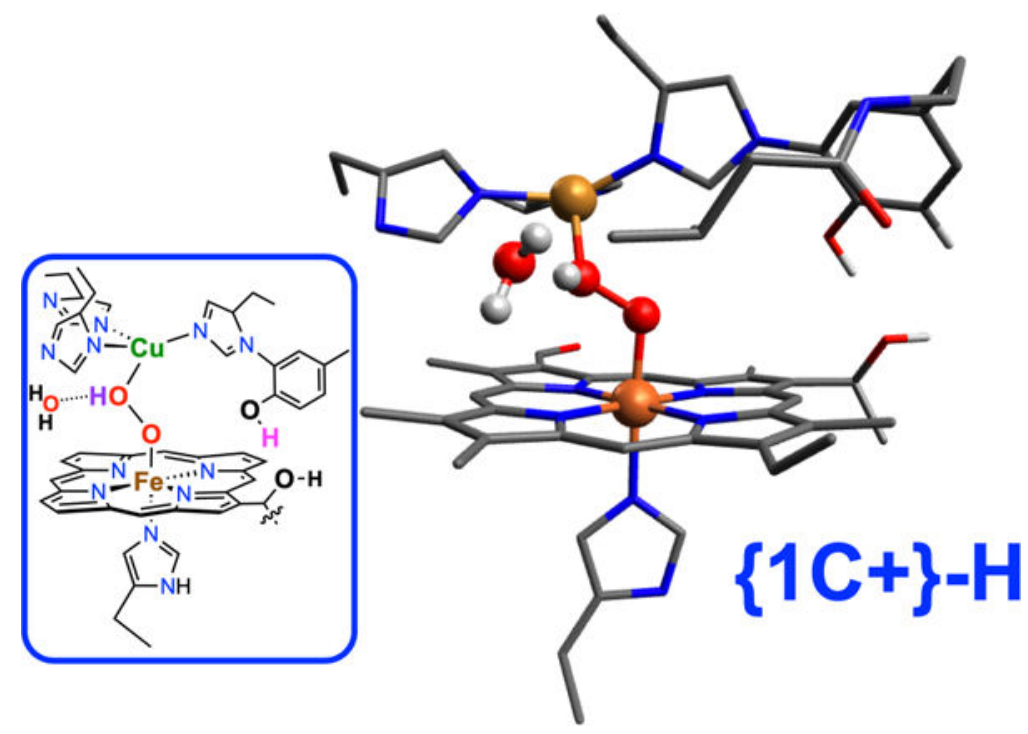

Figure 9.

DFT-optimized structure with a $\mathrm{H}^{+}$transferred from an external donor to the $\mathrm{O}_{\mathrm{cu}}$ atom, where the Tyr remains protonated. 


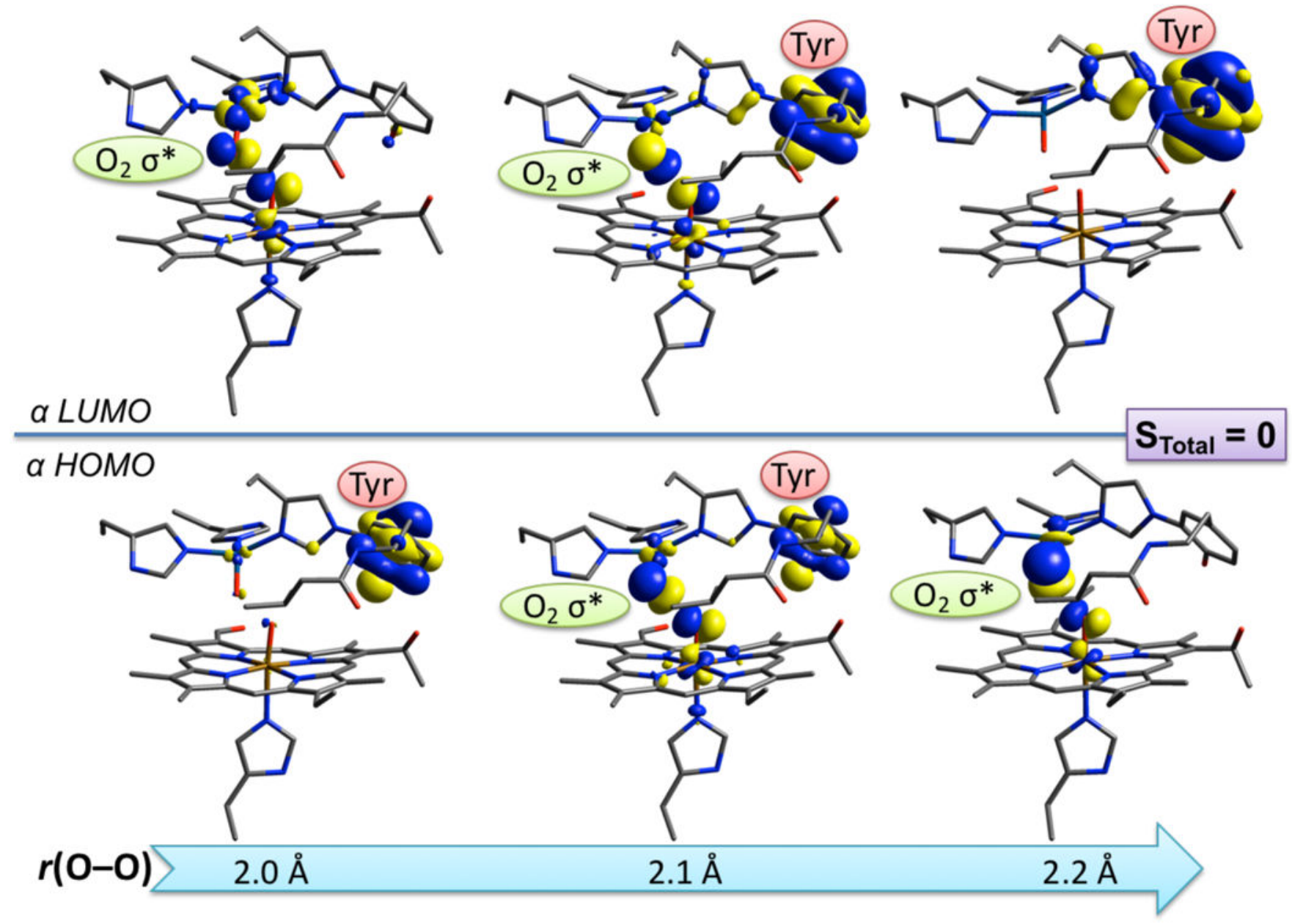

Figure 10.

MO contours along the singlet surface for the PI mechanism, showing the progressive transfer of an a electron from the Tyr HOMO (marked with a red label) into the $\mathrm{O}-\mathrm{O} \sigma^{*}$ (marked with a green label) via the unoccupied $a \mathrm{dx}^{2}-\mathrm{y}^{2}$ as the $\mathrm{O}-\mathrm{O}$ bond elongates, after the transition state. 


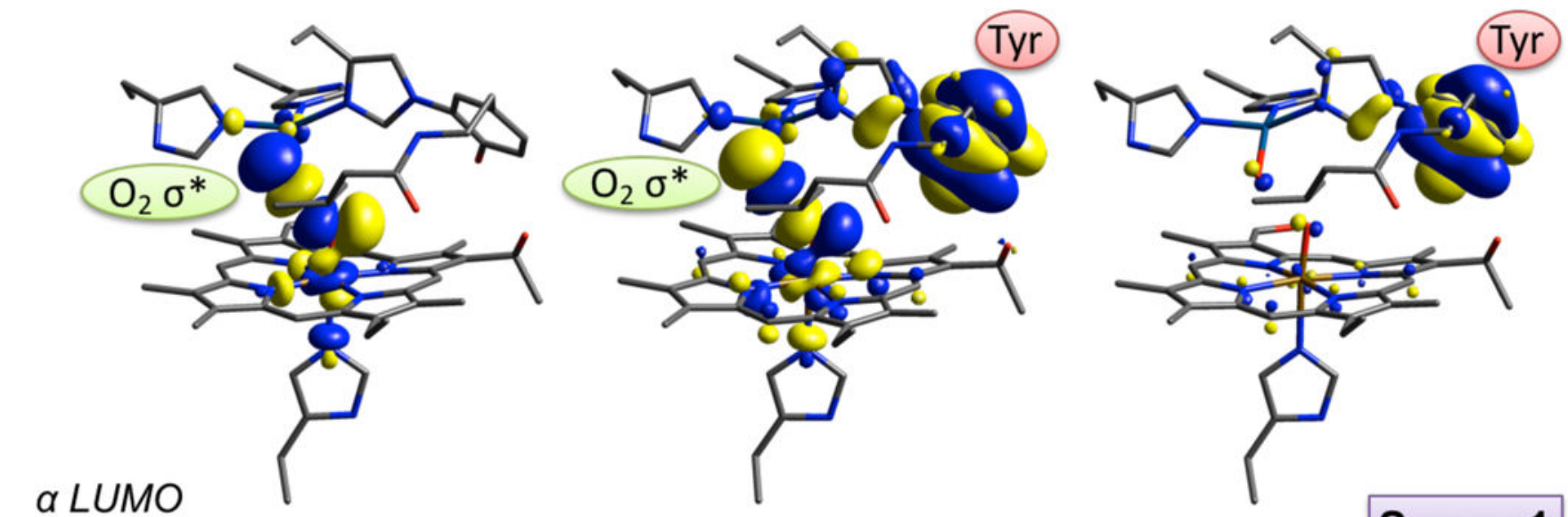

a LUMO
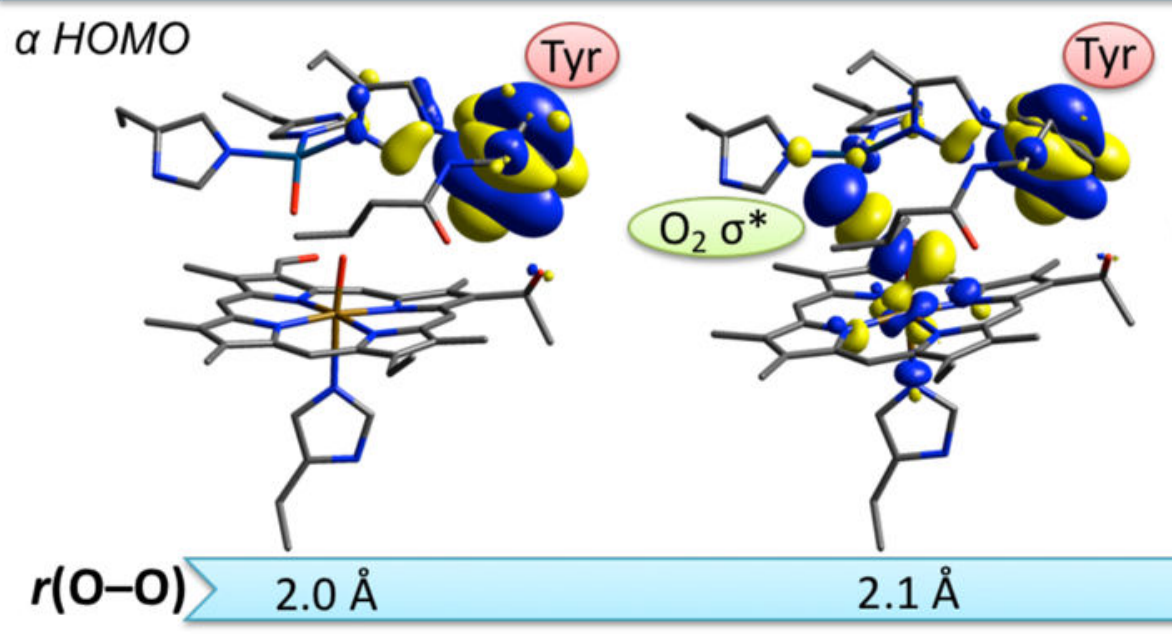

$\mathrm{S}_{\text {Total }}=1$

Figure 11.

MO contours along the triplet surface for the PI mechanism, showing the progressive transfer of an a electron from the Tyr HOMO (marked with a red label) into the $\mathrm{O}-\mathrm{O} \sigma^{*}$ (marked with a green label) as the $\mathrm{O}-\mathrm{O}$ bond elongates, after the transition state. 
Possible Geometric Structures
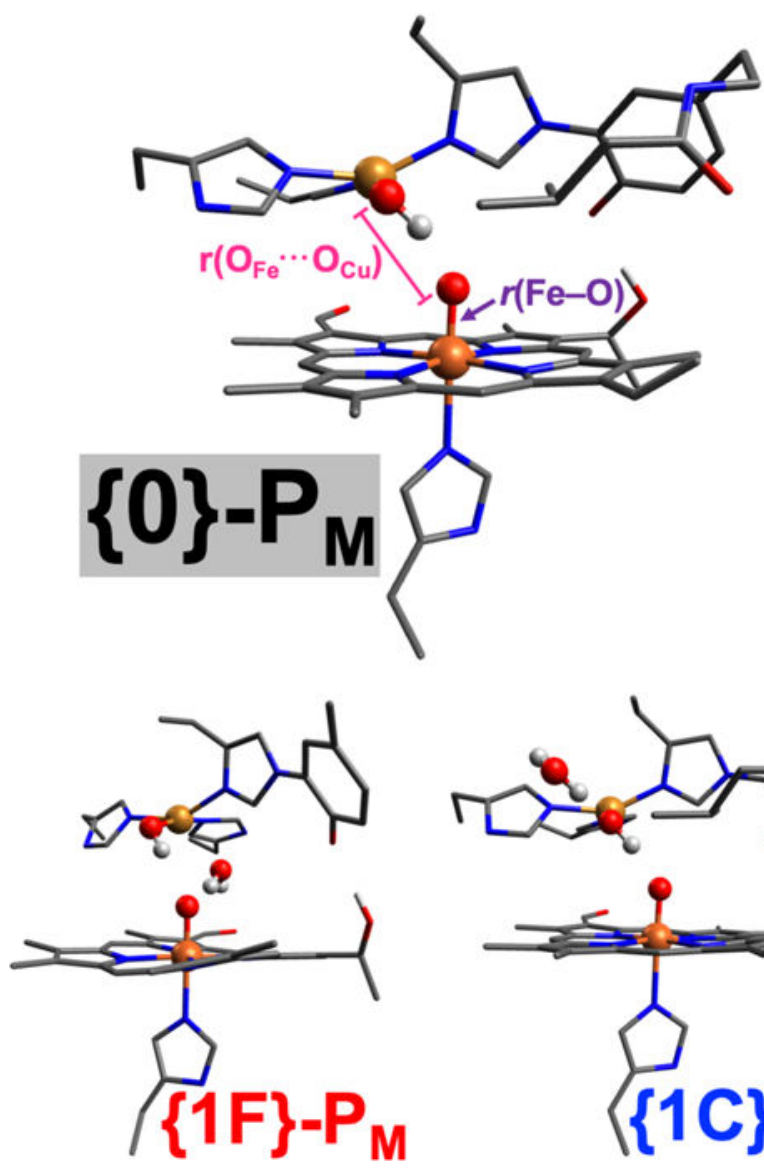

\section{Possible Electronic Structures}
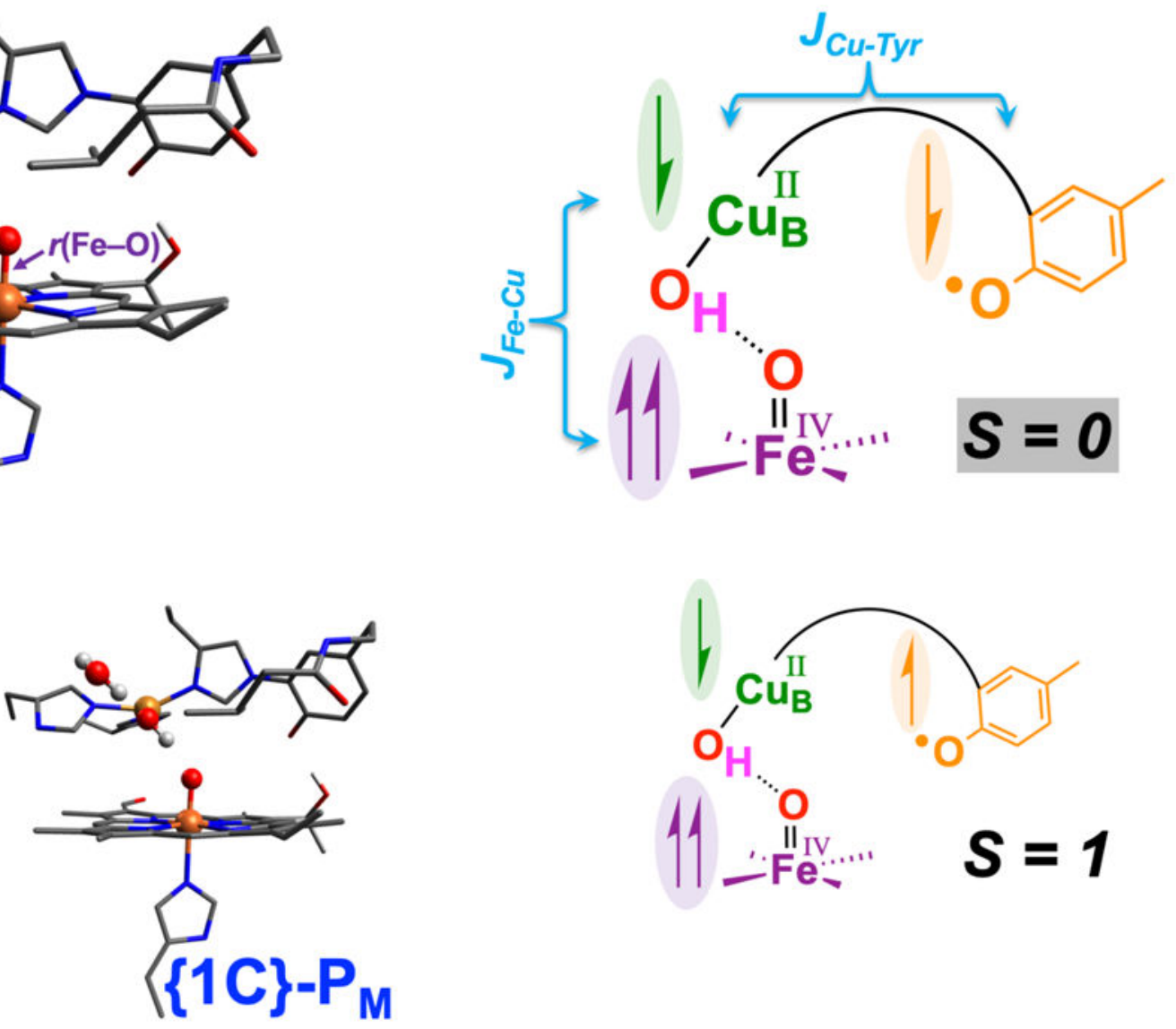

Figure 12.

(left) DFT-optimized structures of $\{\mathbf{0}\}-\mathbf{P}_{\mathbf{M}},\{\mathbf{1 F}\}-\mathbf{P}_{\mathbf{M}}$, and $\{\mathbf{1 C}\}-\mathbf{P}_{\mathbf{M}}$ (as labelled in the figure), representing the possible products generated following $\mathrm{O}-\mathrm{O}$ cleavage via the ProtonInitiated mechanism. Selected bond distances (marked on the $\{\mathbf{0}\}-\mathbf{P}_{\mathbf{M}}$ structure) are given in the text. (right) Localized spins for the $\mathrm{Fe}^{\mathrm{IV}}, \mathrm{Cu}^{\mathrm{II}}$, and $\mathrm{Tyr}{ }^{\circ}$ comprising the singlet and triplet ground states, with the magnetic couplings ( $\mathrm{J}$ ) labelled in the diagram for the singlet (top). The highlighted configurations $\left(\{\mathbf{0}\}-\mathbf{P}_{\mathbf{M}}\right.$ and $\left.\mathbf{S}=0\right)$ are those in closest agreement with available experimental and computational data. Note that Val243 has been removed in the $\{\mathbf{1 F}\}-\mathbf{P}_{\mathbf{M}}$ structure shown for clarity. 

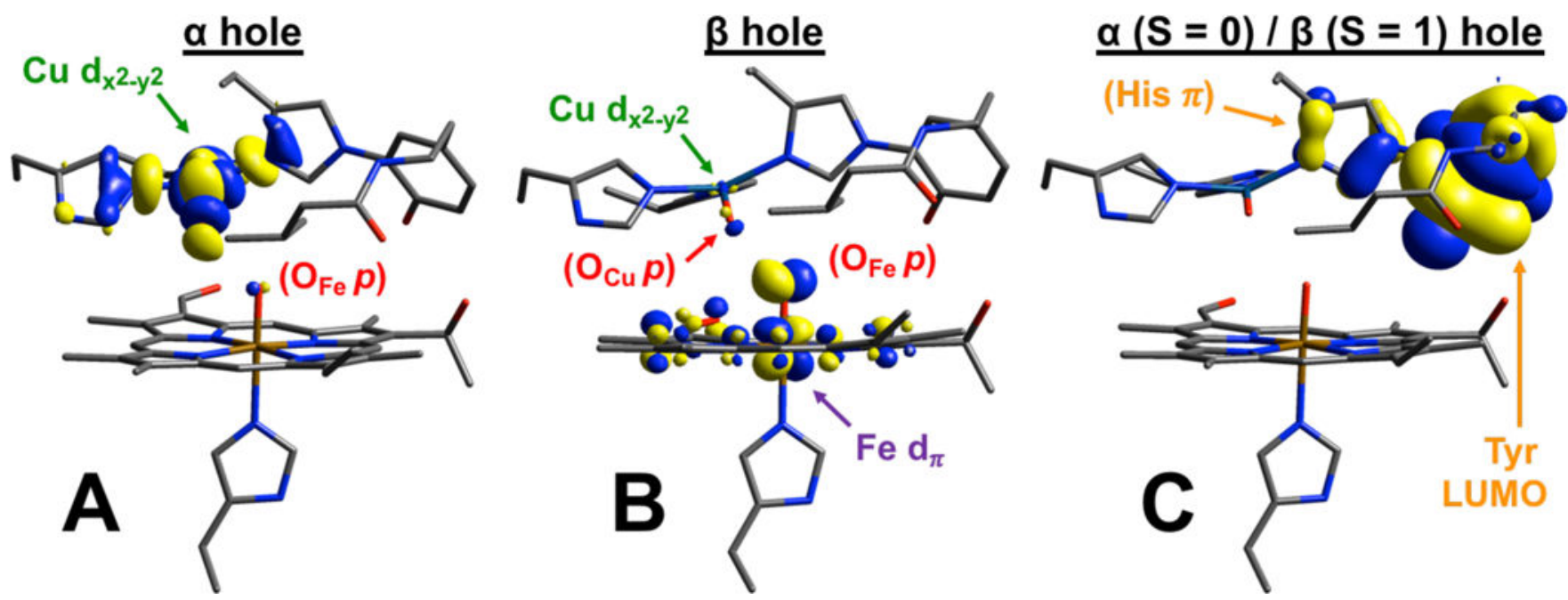

Figure 13.

MOs involved in the superexchange pathway between $\mathrm{Fe}$ and $\mathrm{Cu}$, illustrating (A) $\mathrm{Fe}^{\mathrm{IV}}=\mathrm{O}$ singly occupied orbital character mixed into the $\mathrm{Cu}^{\mathrm{II}}$ hole, and (B) $\mathrm{Cu}^{\mathrm{II}}$ singly occupied orbital character mixed into a hole on $\mathrm{Fe}^{\mathrm{IV}}=\mathrm{O}$. Orbitals labelled in parentheses are doubly occupied. 


\section{Ferromagnetic}

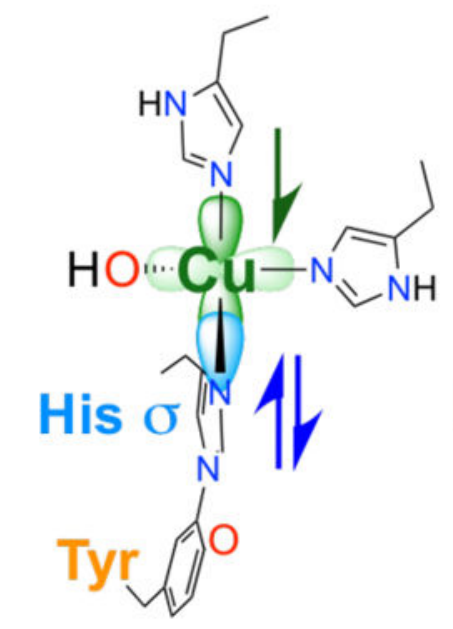

His $\sigma \leftrightarrow \mathrm{Cu}^{\prime \prime}$ LUMO

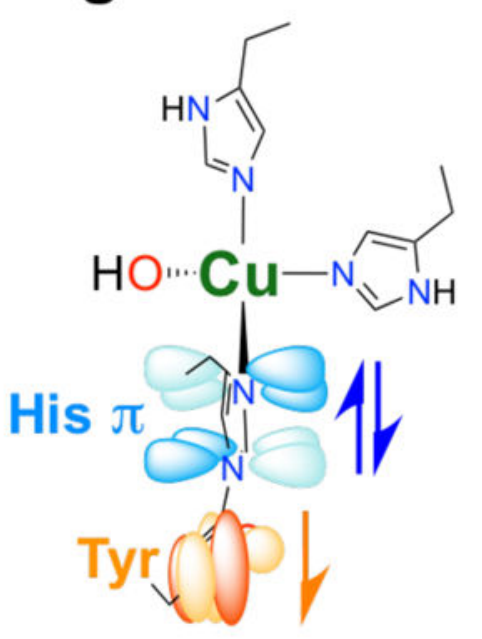

His $\pi \leftrightarrow \mathrm{Tyr}^{\bullet}$ LUMO
Antiferromagnetic

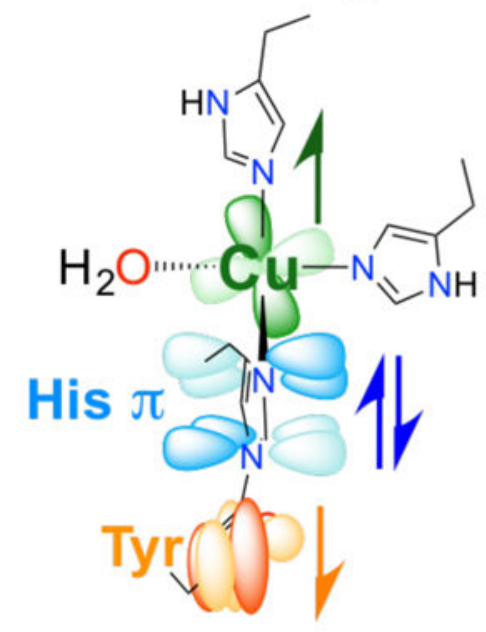

Cu" LUMO $\leftrightarrow$ His $\pi \leftrightarrow$ Tyr• LUMO

Figure 14.

Schematic representation of orbital overlap of the cross-linked His donor orbitals with the half-occupied orbitals on $\mathrm{Cu}^{\mathrm{II}}$ and $\mathrm{Tyr}^{\bullet}$, which leads to either ferromagnetic (left) or antiferromagnetic (right) coupling, depending on whether His $\pi$ character mixes into the $\mathrm{Cu}$ LUMO. Note that the orbitals depicted for ferromagnetic coupling represent those shown in Figure $13 \mathrm{~A}$ and $\mathrm{C}$. 


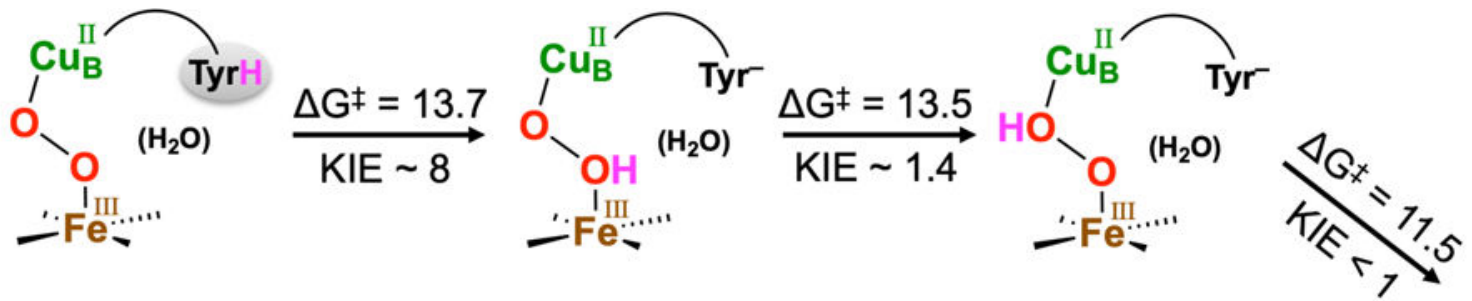

$\{1 F\} \mathrm{H}^{+}$from cross-linked Tyr

$\{1 \mathrm{C}\} \mathrm{H}^{+}$from nearby amino acid

$\left(\mathrm{H}_{2} \mathrm{O}\right)_{\times}$
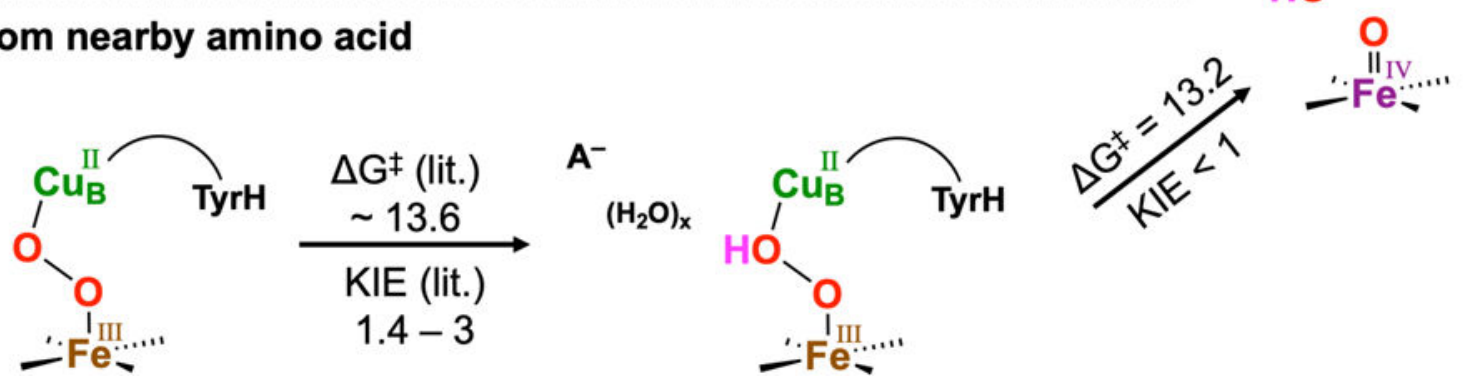

Scheme 1.

Two possible reaction pathways for proton-initiated $\mathrm{O}-\mathrm{O}$ cleavage, with calculated barriers (in $\mathrm{kcal} / \mathrm{mol}$ ) and H/D KIEs for each step. Energies in each model are relative to the optimized "I $\mathrm{I}_{\mathrm{P}}$ " structure. The barriers for PT from a nearby amino acid are calculated using transition state theory, assuming a $\mathrm{p} K_{\mathrm{a}}$ that is 2 units higher than that of the active site Tyr (see text and SI). 